\title{
TMPRSS2 and ADAM17 Cleave ACE2 Differentially and Only Proteolysis by TMPRSS2 Augments Entry Driven by the Severe Acute Respiratory Syndrome Coronavirus Spike Protein
}

\author{
Adeline Heurich, ${ }^{\text {a }}$ Heike Hofmann-Winkler, ${ }^{\text {a }}$ Stefanie Gierer, ${ }^{\text {a }}$ Thomas Liepold, $^{\text {b }}$ Olaf Jahn, ${ }^{\text {b Stefan Pöhlmann }}{ }^{\text {a }}$ \\ Infection Biology Unit, German Primate Center, Göttingen, Germanya; Proteomics Group, Max Planck Institute of Experimental Medicine, Göttingen, Germany ${ }^{b}$
}

\begin{abstract}
The type II transmembrane serine proteases TMPRSS2 and HAT can cleave and activate the spike protein (S) of the severe acute respiratory syndrome coronavirus (SARS-CoV) for membrane fusion. In addition, these proteases cleave the viral receptor, the carboxypeptidase angiotensin-converting enzyme 2 (ACE2), and it was proposed that ACE2 cleavage augments viral infectivity. However, no mechanistic insights into this process were obtained and the relevance of ACE2 cleavage for SARS-CoV S protein (SARS-S) activation has not been determined. Here, we show that arginine and lysine residues within ACE2 amino acids 697 to 716 are essential for cleavage by TMPRSS2 and HAT and that ACE2 processing is required for augmentation of SARS-S-driven entry by these proteases. In contrast, ACE2 cleavage was dispensable for activation of the viral S protein. Expression of TMPRSS2 increased cellular uptake of soluble SARS-S, suggesting that protease-dependent augmentation of viral entry might be due to increased uptake of virions into target cells. Finally, TMPRSS2 was found to compete with the metalloprotease ADAM17 for ACE2 processing, but only cleavage by TMPRSS2 resulted in augmented SARS-S-driven entry. Collectively, our results in conjunction with those of previous studies indicate that TMPRSS2 and potentially related proteases promote SARS-CoV entry by two separate mechanisms: ACE2 cleavage, which might promote viral uptake, and SARS-S cleavage, which activates the $S$ protein for membrane fusion. These observations have interesting implications for the development of novel therapeutics. In addition, they should spur efforts to determine whether receptor cleavage promotes entry of other coronaviruses, which use peptidases as entry receptors.
\end{abstract}

\begin{abstract}
oronaviruses are enveloped RNA viruses which cause enteric, respiratory, and central nervous system diseases in a variety of animals and humans (1). The coronaviruses NL63, 229E, and OC43 are adapted to spread in humans, and infection is usually associated with mild respiratory symptoms (2-8). In contrast, the zoonotic transmission of animal coronaviruses to humans can result in novel, severe diseases. The severe acute respiratory syndrome coronavirus (SARS-CoV), which is believed to have been transmitted from bats via an intermediate host to humans (9-11), is the causative agent of the respiratory disease SARS, which claimed more than 700 lives in 2002-2003 (12). Similarly, the recently emerged Middle East respiratory syndrome coronavirus (MERS-CoV) induces a severe, SARS-related respiratory disease, and its spread is at present responsible for 64 deaths $(13,14)$. The elucidation of the molecular processes underlying the spread and pathogenesis of highly pathogenic coronaviruses is required to devise effective antiviral strategies and is therefore the focus of current research efforts.
\end{abstract}

The coronavirus surface protein spike (S) mediates entry into target cells by binding to a cellular receptor and by subsequently fusing the viral envelope with a host cell membrane $(15,16)$. The receptor binding activity of the $\mathrm{S}$ proteins is located within the S1 subunit, while the $\mathrm{S} 2$ subunit harbors the functional elements required for membrane fusion $(15,16)$. The SARS-CoV S protein (SARS-S) utilizes angiotensin converting enzyme 2 (ACE2) as a receptor for host cell entry $(17,18)$. ACE2, a metallopeptidase, is expressed on major viral target cells, type II pneumocytes and enterocytes (19-22), and its catalytic domain binds to SARS-S with high affinity $(17,23)$. Binding of SARS-S to ACE2 triggers subtle conformational rearrangements in SARS-S, which are believed to increase the sensitivity of the $S$ protein to proteolytic digest at the border between the S1 and S2 subunits $(24,25)$.
Cleavage of the S protein by host cell proteases is essential for viral infectivity (15), and the responsible enzymes constitute potential targets for intervention.

The SARS-CoV can hijack two cellular proteolytic systems to ensure the adequate processing of its $S$ protein. Cleavage of SARS-S can be facilitated by cathepsin L, a pH-dependent endo-/ lysosomal host cell protease, upon uptake of virions into target cell endosomes (25). Alternatively, the type II transmembrane serine proteases (TTSPs) TMPRSS2 and HAT can activate SARS-S, presumably by cleavage of SARS-S at or close to the cell surface, and activation of SARS-S by TMPRSS2 allows for cathepsin L-independent cellular entry (26-28). Both TMPRSS2 and HAT are expressed in ACE2-positive cells in the human lung $(27,29)$, and results obtained with surrogate cell culture systems suggest that TMPRSS2 might play a significant role in SARS-CoV spread in the human respiratory tract (30). Notably, TMPRSS2 and HAT also activate influenza viruses bearing a hemagglutinin with a monobasic cleavage site $(31,32)$ and TMPRSS2 was shown to cleave and activate the $\mathrm{F}$ protein of human metapneumovirus (33), indicating that several human respiratory viruses hijack TTSPs to promote their spread.

The role of host cell proteases in SARS-CoV infection is not limited to cleavage of the $S$ protein: two studies suggest that ACE2 is proteolytically processed by host cell proteases and that process-

Received 8 August 2013 Accepted 5 November 2013

Published ahead of print 13 November 2013

Address correspondence to Stefan Pöhlmann, spoehlmann@dpz.eu.

Copyright @ 2014, American Society for Microbiology. All Rights Reserved.

doi:10.1128/JVI.02202-13 
ing might play an important role in SARS-CoV entry and pathogenesis. It was shown that SARS-S binding to ACE2 triggers processing of ACE2 by a disintegrin and metallopeptidase domain 17 (ADAM17)/tumor necrosis factor $\alpha$-converting enzyme (TACE), and evidence was provided that this process, which facilitates shedding of ACE2 into the extracellular space, promotes uptake of SARS-CoV into cells $(34,35)$. However, it is disputed whether the increased uptake translates into increased infection efficiency (34, 36). Irrespective of its role in entry, the SARS-S-induced shedding of ACE2 might be integral to the development of SARS. Thus, ACE2 expression was shown to protect against experimentally induced lung injury in a mouse model, and evidence for a decreased ACE2 expression in the context of SARS-CoV infection was obtained $(37,38)$. It is therefore conceivable that $\mathrm{S}$ protein-induced, ADAM17-mediated shedding of ACE2 might promote SARS pathogenesis. A more recent study demonstrated that ACE2 is also processed by TMPRSS2 and HAT, and it was suggested that ACE2 cleavage increases SARS-S-mediated entry (28). However, the mechanism underlying augmentation of infection is unclear and the role of ACE2 proteolysis in TMPRSS2/HAT-dependent SARS-S activation is unknown. Similarly, the potential interplay between ACE2 processing by TMPRSS2/HAT and ADAM17 and its consequences for SARS-CoV entry have not been examined.

Here, we show that ACE2 proteolysis by TMPRSS2/HAT accounts for the ability of these proteases to augment SARS-Sdriven entry but is dispensable for SARS-S activation. In addition, we provide evidence that increased SARS-S-mediated entry into TMPRSS2/HAT-expressing cells might be due to augmented viral uptake. Finally, we show that TMPRSS2 and ADAM17 compete for ACE2 cleavage and that only processing by TMPRSS2 promotes SARS-S-driven entry.

\section{MATERIALS AND METHODS}

Cell culture. 293T and Cos-7 cells were maintained in Dulbecco's modified Eagle medium (DMEM; Gibco, Invitrogen) supplemented with 10\% heat-inactivated fetal calf serum (FCS; Biochrom) and 1\% penicillin/ streptomycin sulfate (Cytogen). The cells were grown in a humidified atmosphere at $37^{\circ} \mathrm{C}$ and $5 \% \mathrm{CO}_{2}$.

Plasmids. Expression plasmids for SARS-S and vesicular stomatitis virus $\mathrm{G}$ protein (VSV-G) as well as the plasmid used for production of the Fc-tagged S1 subunit of SARS-S have been described previously (39-41). Plasmids encoding the human transmembrane proteases TMPRSS2, TMPRSS3, TMPRSS4, TMPRSS6, and HAT, as well as murine, porcine, and avian TMPRSS2, murine TMPRSS4, and murine HAT, were also described earlier $(26,29,42,43)$. The sequences encoding the enzymatic inactive proteases TMPRSS2 and HAT with an $\mathrm{N}$-terminal myc tag as well as the ACE2 mutants were generated by overlap-extension PCR and inserted into the plasmids pCAGGS (44) and pcDNA3.1 zeo, respectively. The integrity of all PCR-amplified sequences was confirmed by automated sequence analysis. Finally, for generation of lentiviral pseudotypes, the vector pNL-Luc- $\mathrm{E}^{-} \mathrm{R}^{-}$was employed (45).

Analysis of ACE2 cleavage. For the detection of ACE2 cleavage by TTSPs, 293T cells were cotransfected with an expression plasmid encoding ACE2 and either plasmids encoding the specified proteases or empty plasmid. The medium was replaced with fresh DMEM at 6 to $8 \mathrm{~h}$ posttransfection. At $48 \mathrm{~h}$ posttransfection, the cells were washed with phosphate-buffered saline (PBS) and lysed in radioimmunoprecipitation assay (RIPA) buffer $(0.1 \%$ sodium dodecyl sulfate [SDS], $1 \%$ Triton X-100, 1\% sodium deoxycholate, $50 \mathrm{mM}$ Tris- $\mathrm{HCl}$ [pH 7.3], $150 \mathrm{mM} \mathrm{NaCl}$ ). Subsequently, $2 \times$ SDS loading buffer was added and the lysates were incubated at $95^{\circ} \mathrm{C}$. Thereafter, the lysates were separated by SDS-PAGE and blotted onto nitrocellulose membranes, and ACE2 was detected by staining with either a mouse anti-ACE2 antibody directed against the ectodomain (R\&D Systems) at a dilution of 1:2,000 or with a rabbit anti-ACE2 serum specific for the $\mathrm{C}$ terminus (Abgent) at a dilution of 1:500, followed by incubation with horseradish peroxidase (HRP)-coupled anti-mouse or rabbit secondary antibodies (Dianova). As loading control, expression of $\beta$-actin was detected by employing an anti- $\beta$-actin antibody (Sigma). For the analysis of ADAM17-mediated ACE2 shedding, $10 \mu \mathrm{M}$ phorbol 12myristate 13-acetate (PMA; Sigma) was added for $16 \mathrm{~h}$ to cultures of ACE2-transfected 293T cells. Subsequently, the supernatants were harvested and cleared from cell debris by centrifugation. The proteins present in cleared supernatants were precipitated as described previously (36). In brief, trichloroacetic acid (TCA) was added to supernatants, the mixtures were incubated for $30 \mathrm{~min}$ at $4^{\circ} \mathrm{C}$, and precipitated proteins were pelleted through centrifugation at $14,000 \mathrm{rpm}$ for $5 \mathrm{~min}$. Subsequently, the pellet was washed twice with ice-cold acetone and then resuspended in alkaline loading buffer (50 mM Tris [pH 8], 2\% SDS, $100 \mathrm{mM}$ dithiothreitol [DTT], $10 \%$ glycerol, bromophenol blue) and incubated at $95^{\circ} \mathrm{C}$ before analysis by SDS-PAGE and immunoblotting as described above. The program Image (46) was employed for signal quantification.

Analysis of SARS-S-driven host cell entry. The SARS-S-mediated host cell entry was analyzed by employing a lentiviral vector system, as described previously (40). In brief, lentiviral pseudotypes were produced by cotransfecting $293 \mathrm{~T}$ cells with the HIV-1-derived vector pNLLuc- $\mathrm{E}^{-} \mathrm{R}^{-}$and expression plasmids for SARS-S, VSV-G, or empty plasmid (pcDNA). At 6 to $8 \mathrm{~h}$ posttransfection, the culture medium was replaced with fresh medium, and at $48 \mathrm{~h}$ posttransfection, the supernatants were harvested, passed through $0.45-\mu \mathrm{m}$-pore-size filters, aliquoted, and stored at $-80^{\circ} \mathrm{C}$. To analyze the impact of TMPRSS2 and HAT on SARS-S-driven transduction, plasmids encoding the receptor ACE2 or ACE2 mutants were cotransfected with plasmids encoding the indicated proteases or empty plasmid. One day prior to infection, the target cells were seeded in 96-well plates at 30,000 cells/well. Subsequently, pseudotypes were added and the cells were incubated for $6 \mathrm{~h}$ at $37^{\circ} \mathrm{C}$. Thereafter, the medium was replaced with fresh medium. Finally, the luciferase activities in cell lysates were determined at $72 \mathrm{~h}$ postransduction using a commercially available kit (Promega).

Modulation of SARS-S-driven host cell entry. The cathespin B/L inhibitor MDL28170 (Calbiochem), the ADAM17 inhibitor TAPI-1 (Calbiochem), or PMA (Sigma) was diluted in solvent as recommended by the manufacturers. For the analysis of entry inhibition by MDL28170, target cells expressing ACE2 or coexpressing ACE2 and protease were incubated with inhibitor $(10 \mu \mathrm{M}$ final concentration) or solvent alone for $60 \mathrm{~min}$ before pseudotypes were added. After incubation at $37^{\circ} \mathrm{C}$ for $8 \mathrm{~h}$, the supernatants were removed and fresh culture medium without inhibitor was added. Transduction efficiency was determined at $72 \mathrm{~h}$ after the addition of pseudotypes as described above. In order to determine the impact of TAPI-1 and PMA on SARS-S-dependent transduction, target cells were incubated with pseudotypes at $4^{\circ} \mathrm{C}$ for $1 \mathrm{~h}$ followed by removal of unbound particles by washing. Subsequently, the indicated concentrations of TAPI-1 or PMA (see the legend to Fig. 8) were added and the cultures incubated at $37^{\circ} \mathrm{C}$ for $8 \mathrm{~h}$. Thereafter, the culture supernatants were removed and replaced by fresh culture medium without TAPI- 1 or PMA. Transduction efficiency was determined at $72 \mathrm{~h}$ after the addition of pseudotypes.

ACE2 surface expression. For analysis of ACE2 surface expression, plasmids encoding the ACE2 wild type (wt) or the specified ACE2 mutants were transiently transfected into $293 \mathrm{~T}$ cells. At $48 \mathrm{~h}$ posttransfection, the cells were detached and washed with fluorescence-activated cell sorter (FACS) buffer $(1 \times$ PBS, $5 \%$ FCS, 2 mM EDTA) and stained with a goat anti-ACE2 antiserum (R\&D Systems). After binding of the primary antibodies for $45 \mathrm{~min}$ at $4^{\circ} \mathrm{C}$, cells were washed three times with FACS buffer and incubated for $45 \mathrm{~min}$ at $4^{\circ} \mathrm{C}$ with $\mathrm{Cy} 5$-coupled anti-goat secondary antibody (Dianova). After three washes with FACS buffer, the cells were fixed with $2 \%$ paraformaldehyde (PFA) and analyzed in a Becton, Dick- 
inson LSR II flow cytometer. FCS Express software (De Novo Software) was employed for data analysis.

High-salt washes of ACE2 and protease-coexpressing cells. In order to prevent retention of ACE2 cleavage fragments at the cell surface, the ACE2 and protease-coexpressing cells were pelleted and incubated with high-salt buffer $(0.5 \mathrm{M}, 1 \mathrm{M}$, and $1.5 \mathrm{M} \mathrm{NaCl})$ on ice. Subsequently, the cells were pelleted again and the supernatants were collected. The proteins present in cleared supernatants were precipitated as described previously (36), and the presence of ACE2 in cell pellets and supernatants was analyzed by Western blotting as specified above.

Cleavage of recombinant ACE2 and analysis of cleavage sites by mass spectrometry. For the analysis of cleavage of isolated ACE2, $1 \mu \mathrm{g}$ of recombinant ACE2 (R\&D Systems) was incubated with $0.2 \mu \mathrm{g}$ of recombinant HAT (R\&D Systems) in assay buffer (50 mM Tris, $0.05 \%$ [wt/vol], and Brij 35 [pH 9.5]) for $2 \mathrm{~h}$ at $37^{\circ} \mathrm{C}$ in a total volume of $25 \mu \mathrm{l}$. Subsequently, the reactions were stopped by the addition of SDS loading buffer, and the reaction products were analyzed by $12.5 \%$ SDS-PAGE and Western blotting. For the analysis of cleavage sites by mass spectrometry (MS), ACE2 cleavage products were separated on precast NuPAGE bis-Tris 4 to $12 \%$ gradient gels using a morpholinepropanesulfonic acid buffer system according to the manufacturer (Invitrogen). After colloidal Coomassie staining, gel bands were excised, and one part of the band was subjected to in-gel digestion with trypsin, while endoproteinase Asp-N was used for the other part. In-gel digestion and mass spectrometric analysis of the proteolytic peptides by matrix-assisted laser desorption ionization-time of flight (MALDI-TOF) MS on an Ultraflex MALDI-TOF/TOF mass spectrometer (Bruker Daltonics) were performed as described previously (43, 47). Extracted peptides were dried, redissolved in $0.5 \%$ trifluoroacetic acid $/ 0.1 \%$ octyl-glucopyranoside, and spotted onto an AnchorChip target (Bruker Daltonics) precoated with $\alpha$-cyano-4-hydroxycinnamic acid. Preparation was according to either the standard thin-layer affinity method (47) or an adapted method to improve coverage of small hydrophilic peptides. For this purpose, $0.5 \mu \mathrm{l}$ was spotted onto the matrix surface, let dry, and washed once with ammonium dihydrogen phosphate (10 $\mathrm{mM}$ in $0.1 \%$ trifluoroacetic acid [TFA]).

Cellular uptake of SARS-S. 293T cells were seeded on coated coverslips, transfected with plasmids encoding ACE2 and TMPRSS2 or empty vector, and incubated with the Fc-tagged S1 subunit of SARS-S for $1 \mathrm{~h}$. Incubation was performed at $4^{\circ} \mathrm{C}$ to allow binding but not uptake or at $37^{\circ} \mathrm{C}$ to allow both processes. Subsequently, the cells were prepared for confocal microscopy. For this, the cells were washed three times with PBS followed by 20 min of fixation with $4 \%$ PFA. To stop the PFA fixation, the cells were treated with $50 \mathrm{mM} \mathrm{NH}_{4} \mathrm{C}$ for $10 \mathrm{~min}$. Subsequently, the cells were washed three times with PBS and then permeabilized by treatment with $0.2 \%$ Triton $\mathrm{X}-100$ for $15 \mathrm{~min}$. Thereafter, the cells were washed again three times with PBS and then blocked with $3 \%$ bovine serum albumin (BSA). Bound SARS-S1-Fc fusion protein was detected by using a fluorescein isothiocyanate (FITC)-coupled, anti-human Ig-specific secondary antibody (Dianova), while ACE2 expression was detected by staining with a mouse anti-ACE2 antibody, followed by staining with Red-Xcoupled anti-mouse secondary antibody (Dianova). Finally, the cells were washed again, the coverslips were embedded in mounting medium, and staining was analyzed by confocal microscopy employing a LSM5 Pa confocal microscope (Carl Zeiss). The FACS-based analysis of SARS-S1-Fc binding to cells was conducted as described previously (41).

Statistical analysis. Statistical significance was calculated using twotailed Student's $t$ test for independent samples.

\section{RESULTS}

TMPRSS2, HAT, and hepsin cleave ACE2. We first examined if ACE2 cleavage by TTSPs is detectable in transiently transfected $293 \mathrm{~T}$ cells, which we routinely employ to assess SARS-S-driven cell-cell and virus-cell fusion. Indeed, coexpression of ACE2 and TMPRSS2 or HAT of human and animal origin resulted in ACE2 cleavage with a C-terminal ACE2 fragment of $13 \mathrm{kDa}$ being readily detectable in cell lysates (Fig. 1A and B, middle panels). ACE2 processing into a $13-\mathrm{kDa}$ C-terminal fragment was also observed for hepsin, while TMPRSS3, TMPRSS4, and TMPRSS6 did not facilitate ACE2 proteolysis (Fig. 1A and B, middle panels), despite efficient expression in transiently transfected cells (not shown). Production of the $13-\mathrm{kDa}$ ACE2 fragment was dependent on the enzymatic activities of TMPRSS2 and HAT, since the fragment was not generated in cells expressing enzymatically inactive mutants of these proteases (Fig. 1C). Finally, titration experiments showed that the efficiency of ACE2 cleavage was dependent on the protease expression level. Thus, low protease expression resulted in the generation of additional cleavage products of approximately 15 to $17 \mathrm{kDa}$ (Fig. 1C), which likely represent incompletely processed C-terminal fragments of ACE2. In sum, our results demonstrate that TMPRSS2 and HAT remove a short C-terminal fragment from ACE2, in keeping with previous findings (28). In addition, a new ACE2-processing TTSP, hepsin, was identified, which cleaves ACE2 in a manner similar to that observed for TMPRSS2 and HAT.

Residue R621 is dispensable for cleavage of cellular ACE2. The identification of the TMPRSS2 and HAT cleavage sites in ACE2 is a prerequisite to understanding how ACE2 cleavage by these proteases impacts SARS-S-driven entry. We employed recombinant ACE2 and HAT, both of which are commercially available, to address this question. Incubation of ACE2 with HAT but not reaction buffer alone produced an 80-kDa fragment (Fig. 2A), indicating that ACE2 proteolysis by HAT in cells can be reproduced in vitro with recombinant proteins. To identify the cleavage site, we performed a mass spectrometric peptide mapping analysis of intact ACE2 and the $80-\mathrm{kDa}$ fragment using two different proteases with a complementary cleavage specificity, trypsin and endoproteinase Asp-N. In contrast to the peptide maps of intact ACE2, no peptides matching the C-terminal sequence of amino acids 603 to 733 were detectable in the trypsin/Asp- $\mathrm{N}$ digests of the $80-\mathrm{kDa}$ fragment (Fig. 2B). This finding, together with the observation that the Asp-N cleavage product 598-DQSIKVRISLKSAL G-612 is present in the Asp-N digest of intact ACE2 but not in that of the $80-\mathrm{kDa}$ fragment (Fig. 2C), indicated that the HAT cleavage site resides in this 15 -amino-acid sequence. When we screened the Asp- $\mathrm{N}$ digests for the corresponding candidate peptide species, we found the Asp-N cleavage product 598-DQSIKVR-604 to be present in the Asp-N digest of the $80-\mathrm{kDa}$ fragment but not in that of intact ACE2 (Fig. 2D), indicating that the cleavage occurred at R604, in agreement with the preference of HAT for cleavage Cterminally of Arg (48). These results were confirmed by mass spectrometric sequencing of peptides 598-DQSIKVRISLKSALG-612 and 598-DQSIKVR-604 (data not shown). Thus, mass spectrometric analysis revealed that the $80-\mathrm{kDa}$ fragment was generated upon HAT-dependent proteolysis of recombinant ACE2 at residue R604, corresponding to R621 of cellular ACE2. In order to elucidate if cellular ACE2 is also cleaved by HAT at this site or at an arginine or lysine residue located in close proximity, we generated K619A, R621A, K619A R621A, and K625A mutants. However, all ACE2 mutants were cleaved with an efficiency similar to that of the ACE2 wt in cells coexpressing HAT or TMPRSS2 (Fig. 2E). These findings indicate that the cleavage site in recombinant ACE2 might be located at R604, while the corresponding residue in cellular ACE2 and R621, as well as nearby basic residues, are dispensable for cleavage. 
A)

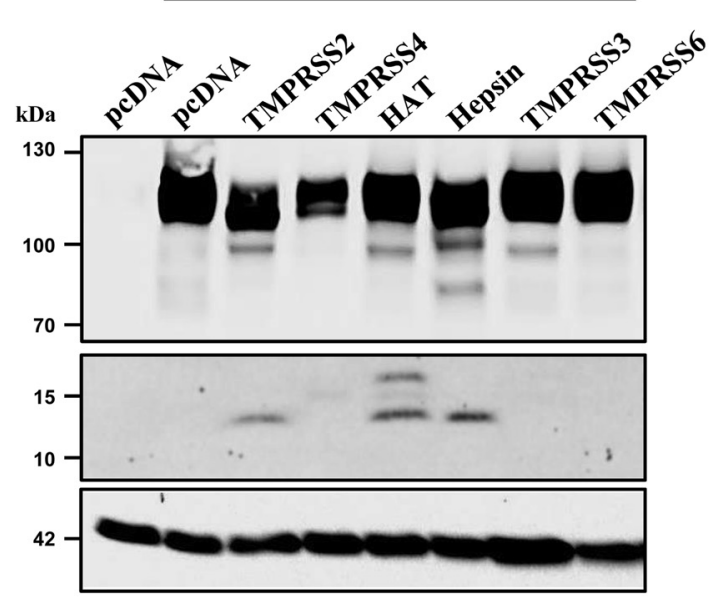

C)

ACE2

ACE2

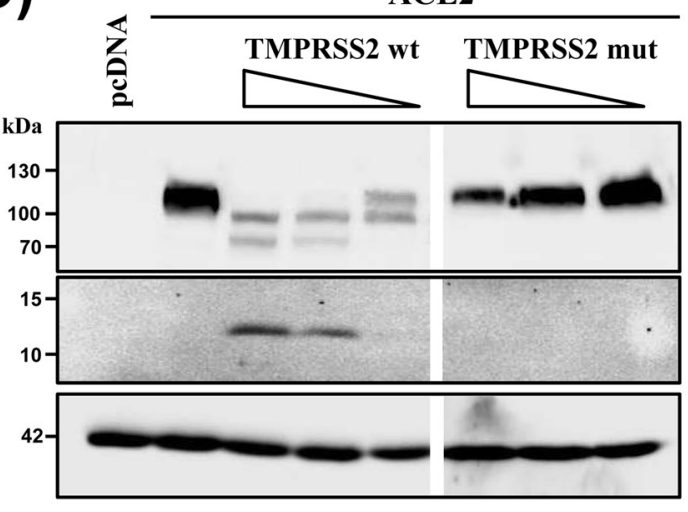

B)
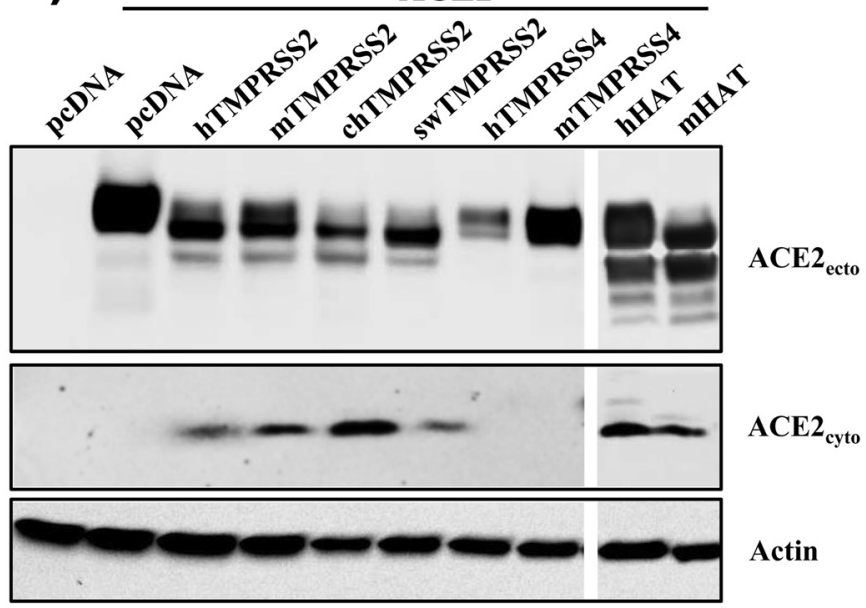

ACE2 cyto

Actin

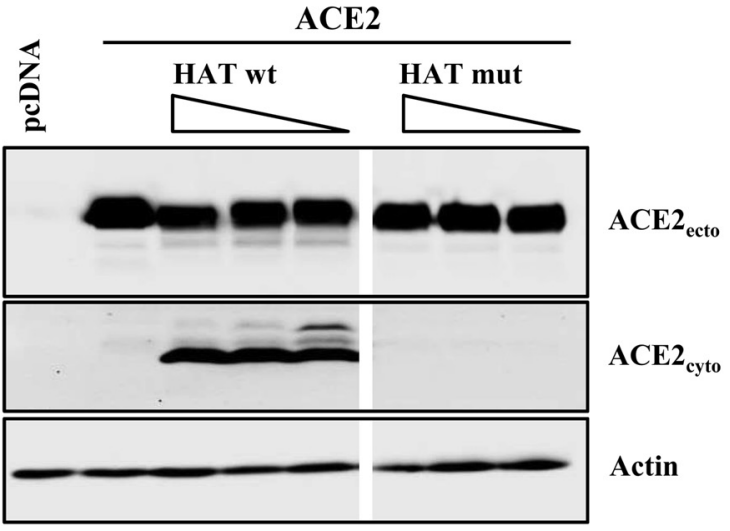

FIG 1 Cleavage of ACE2 by type II transmembrane serine proteases. (A) Plasmids encoding ACE2 and the indicated proteases were transiently cotransfected into 293T cells. Cells cotransfected with empty plasmid (pcDNA) or transfected with empty plasmid alone served as negative controls. The transfected cells were lysed and the lysates analyzed by Western blotting using an ACE2 monoclonal antibody directed against the ACE2 ectodomain (top panel) or a polyclonal antibody directed against the $\mathrm{C}$ terminus of ACE2 (middle panel). Detection of $\beta$-actin in cell lysates served as a loading control (bottom panel). (B) The experiment was carried out as described for panel A, but proteases from the indicated species were analyzed. The results of two gels run in parallel are shown. (C) The experiment was carried out as described for panel A, but different amounts of plasmid encoding TMPRSS2 and HAT wild types or catalytically inactive proteases (TMPRSS2 mut, HAT mut) were cotransfected. Ecto, ectodomain; cyto, cytoplasmic domain; h, human; m, mouse; ch, chicken; sw, swine.

Arginine and lysine residues within amino acids 697 to 716 are essential for efficient ACE2 cleavage by TMPRSS2 and HAT. Since work with recombinant proteins did not allow the identification of the ACE2 site cleaved by HAT or TMPRSS2 in cells, we next employed mutagenesis to identify the cleavage site(s) of these proteases. Sequence analysis revealed the presence of five clusters of arginine and lysine residues located between R619 and the transmembrane domain of ACE2 (residues 741 to 761), which could be recognized by TTSPs (Fig. 3A). In order to assess the importance of these clusters for ACE2 cleavage by TMPRSS2 and HAT, we mutated the clustered arginine and lysine residues to alanine, resulting in mutants $\mathrm{C} 0$ to $\mathrm{C} 4$ (Fig. 3A). In addition, we combined a mutation of cluster 0 , which harbors the residue (R621) cleaved in the context of recombinant proteins, with mutations of the remaining clusters, giving yield to mutants $\mathrm{C} 0+\mathrm{C} 1$ to $\mathrm{C} 0+\mathrm{C} 4$ (Fig. 3A). Expression of all ACE2 mutants in cell lysates was readily detected by Western blotting, although expression of mutants $\mathrm{C} 2$ and $\mathrm{C} 0+\mathrm{C} 2$ was reduced compared to expression of the ACE wt (Fig. 3B and C, top panels). Analysis of
ACE2 cleavage revealed that mutation of lysine and arginine residues in clusters 0 to 3 did not interfere with ACE2 processing by TMPRSS2 and HAT (Fig. 3B and C, bottom panels). In contrast, mutation of the arginine and lysine residues within cluster 4 markedly reduced cleavage by both TMPRSS2 and HAT (Fig. 3B, bottom panel), and cleavage was further diminished when a mutation of cluster 4 was combined with a mutation of cluster $\mathrm{C} 0$ (mutant $\mathrm{C} 0+\mathrm{C} 4$ ) (Fig. 3C, bottom panel, and Fig. 3D). These results identify the arginine and lysine residues within cluster 4 (amino acids 697 to 716) as essential for ACE2 proteolysis by TMPRSS2 2 and HAT and suggest that cluster 0 (amino acids 619 to 625) contributes to efficient cleavage of cluster 4.

ACE2 cleavage is essential for TMPRSS2- and HAT-mediated augmentation of SARS-S-driven transduction. We next used our ACE2 mutants to investigate the role of ACE2 proteolysis in the TMPRSS2- and HAT-dependent enhancement of SARS-S-driven entry. As a prerequisite to these studies, we first assessed surface expression and receptor function of the ACE2 mutants in the absence of protease expression. Surface expression of most 


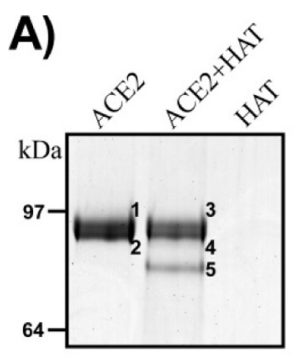

B)

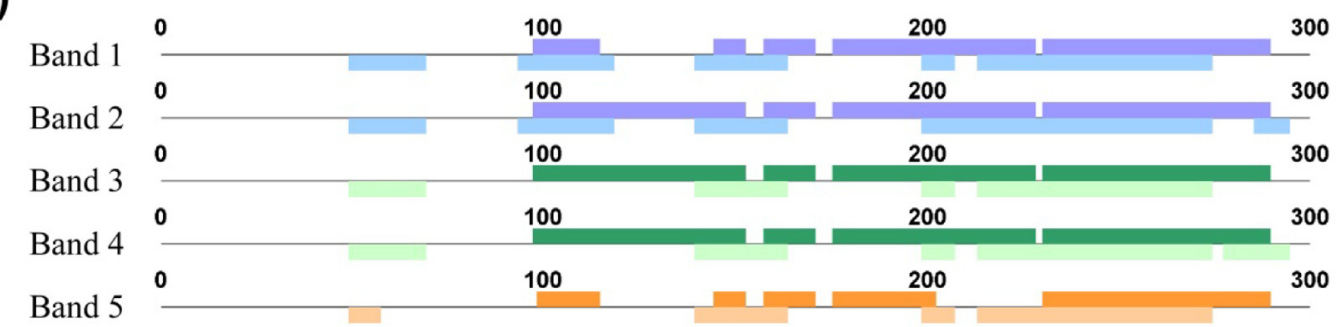

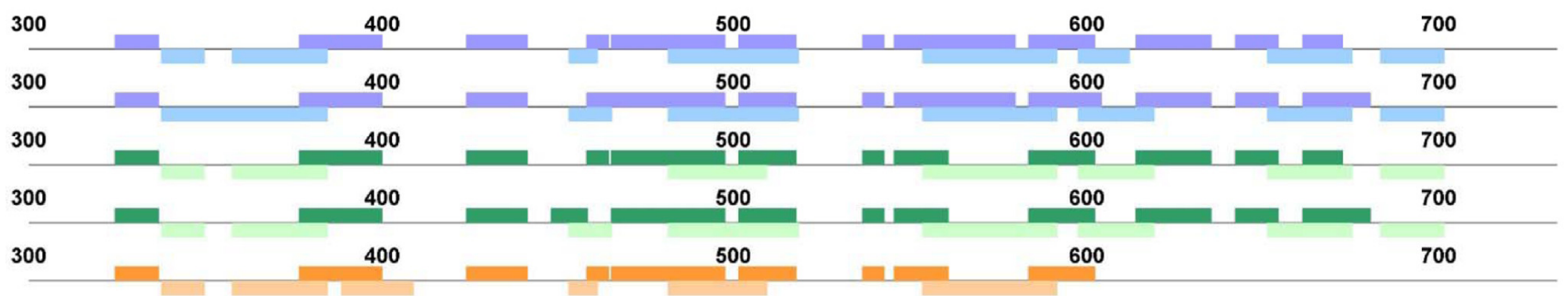

C)

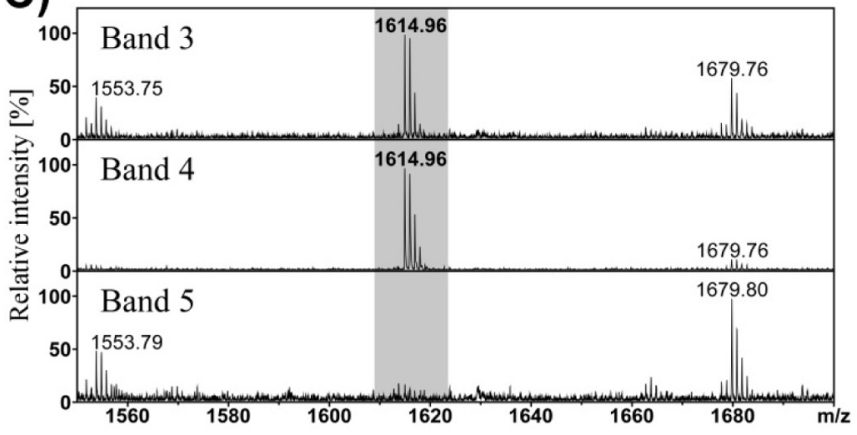

D)

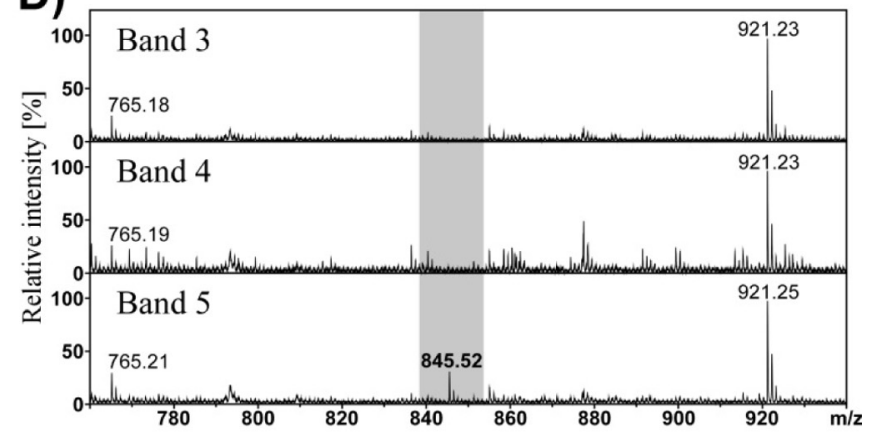

E)

ACE2 + pcDNA

ACE2 + TMPRSS2

$\mathrm{ACE} 2+\mathrm{HAT}$

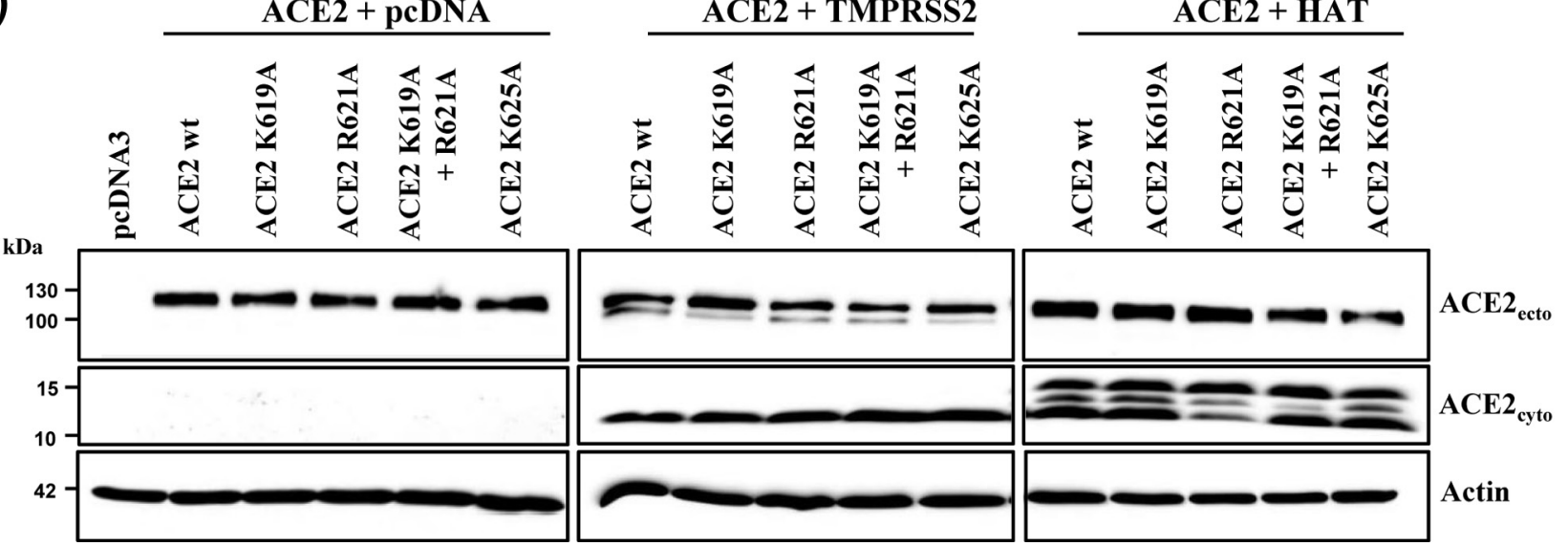

FIG 2 Residue R621 is the HAT cleavage site in recombinant ACE2 but is not essential for cleavage of cellular ACE2 by TMPRSS2 and HAT. (A) Coomassiestained SDS-PAGE gel showing that recombinant ACE2 (apparently migrating as a double band around $90 \mathrm{kDa}$ in this gel system, bands 1 to 4 ) is cleaved into an $80-\mathrm{kDa}$ fragment (band 5) upon incubation with HAT. Note that the $80-\mathrm{kDa}$ fragment does not appear as a double band, suggesting that the differences in the electrophoretic mobility of intact ACE2 may be due to ragged C-terminal sequences (e.g., absence of the 10-His tag as stated in the product information for recombinant ACE2 [R\&D Systems]). (B) Bands 1 to 5 were excised and subjected to mass spectrometric peptide mapping with trypsin and endoproteinase Asp-N, respectively. Visualization of peptide assignments to the ACE2 sequence (upper bars, trypsin; lower bars, Asp-N) shows the absence of the C-terminal part (amino acids 603 to 733 ) in the 80-kDa fragment. (C and D) Mass spectrometric analysis of Asp-N digests of ACE2 (bands 3 and 4) and its cleavage product (band 5). In the zoomed-in mass spectra in panel C, the mass signals at $m / z 1,614.96$ (highlighted in gray) represent the Asp-N cleavage product 598-DQSIKVRISLK SALG-612 $\left([\mathrm{M}+\mathrm{H}]^{+}{ }_{\text {calc }}=1,614.954\right)$. Its presence in intact ACE2 (bands 3 and 4, upper and middle panels) together with its absence in the 80-kDa fragment (band 5, lower panel) indicated that the HAT cleavage site resides within this sequence. In the zoomed-in mass spectra in panel $\mathrm{D}$, the mass signal at $m / z 845.52$ (highlighted in gray) represents the Asp-N cleavage product 598-DQSIKVR-604 ([M+H ${ }^{+}{ }_{\text {calc }}=845.484$ ). Its absence in intact ACE2 (bands 3 and 4, upper and middle panels) together with its presence in the $80-\mathrm{kDa}$ fragment (band 5, lower panel) revealed R604 as the HAT cleavage site. (E) Plasmids encoding the ACE2 wt or the indicated ACE2 mutants jointly with plasmids encoding TMPRSS2 or HAT were transiently cotransfected into 293T cells. The transfected cells were lysed and the lysates analyzed by Western blotting using an ACE2 monoclonal antibody directed against the ACE2 ectodomain (top panel) or a polyclonal antibody directed against the $\mathrm{C}$ terminus of ACE2 (middle panel). Detection of $\beta$-actin in cell lysates served as a loading control (bottom panel). Ecto, ectodomain; cyto, cytoplasmic domain. 
A)
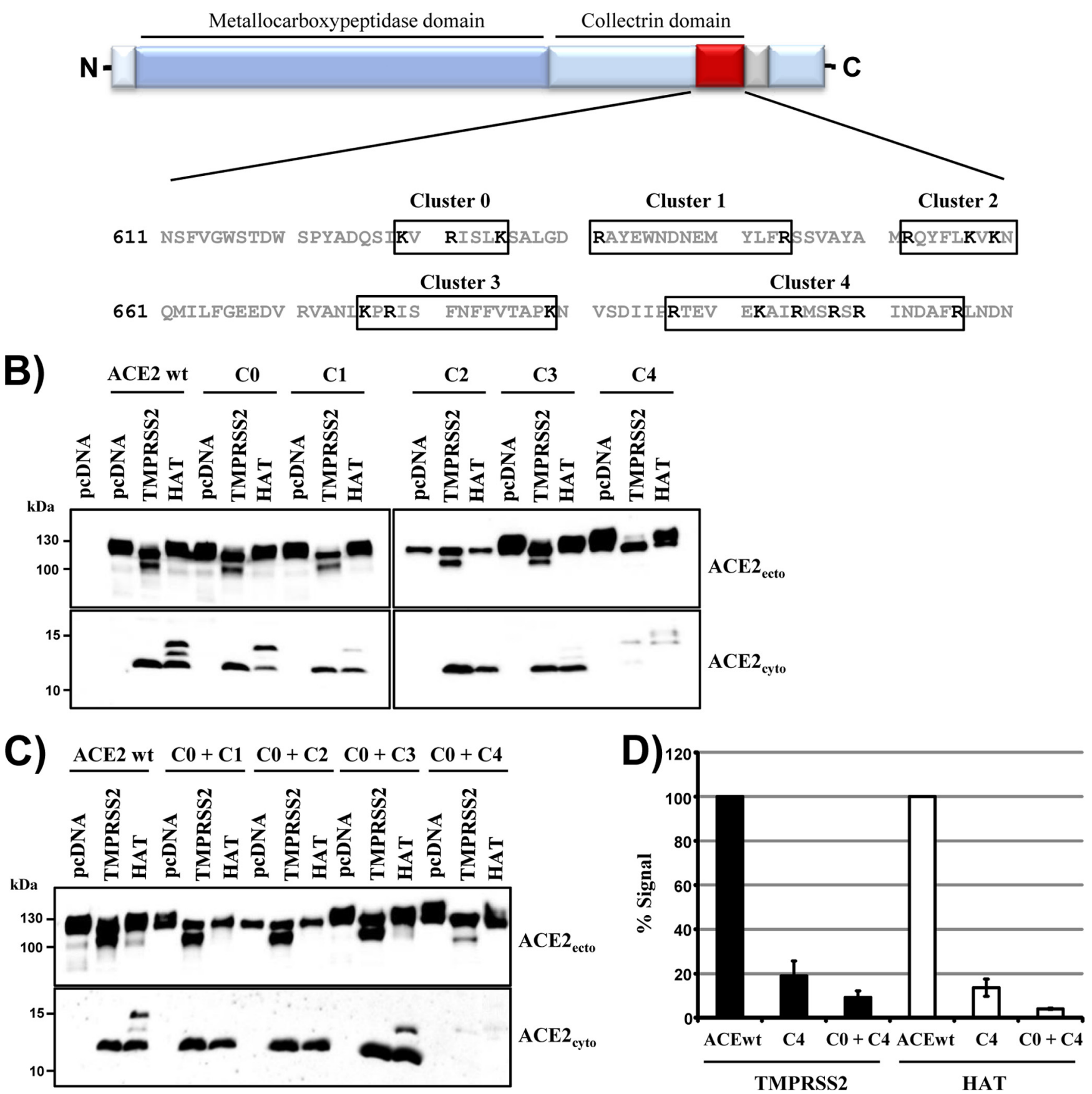

FIG 3 Arginine and lysine residues within ACE2 amino acids 697 to 716 are essential for ACE2 cleavage by TMPRSS2 and HAT. (A) The domain organization of ACE2 is depicted schematically. The membrane-proximal region of ACE2 potentially harboring the TMPRSS2 and HAT cleavage site is highlighted, and its amino acid sequence is provided. Five clusters of arginine and lysine residues were identified in the membrane-proximal sequence, and their position is indicated by boxes. The residues were mutated to alanine, resulting in $\mathrm{ACE} 2$ mutants $\mathrm{C} 0, \mathrm{C} 1, \mathrm{C} 2, \mathrm{C} 3$, and $\mathrm{C} 4$. In addition, mutant $\mathrm{C} 0$ was combined with the remaining mutants, resulting in double mutants $\mathrm{C} 0+\mathrm{C} 1, \mathrm{C} 0+\mathrm{C} 2, \mathrm{C} 0+\mathrm{C} 3$, and $\mathrm{C} 0+\mathrm{C} 4$. (B and C) Plasmids encoding the ACE2 wt or the indicated ACE2 mutants jointly with plasmids encoding TMPRSS2 or HAT or no protease (pcDNA) were transiently cotransfected into 293T cells. The transfected cells were lysed and the lysates analyzed by Western blotting using an ACE2 monoclonal antibody directed against the ACE2 ectodomain (top panels) or a polyclonal antibody directed against the C terminus of ACE2 (bottom panels). (D) The intensity of the C-terminal cleavage fragment observed upon processing of the ACE2 wt or the indicated ACE2 mutants was quantified via ImageJ software. The average signals measured upon analysis of at least three independent Western blots are shown. Error bars indicate standard errors of the mean (SEM). The signal measured upon cleavage of the ACE2 wt was set as 100\%. Ecto, ectodomain; cyto, cytoplasmic domain. 

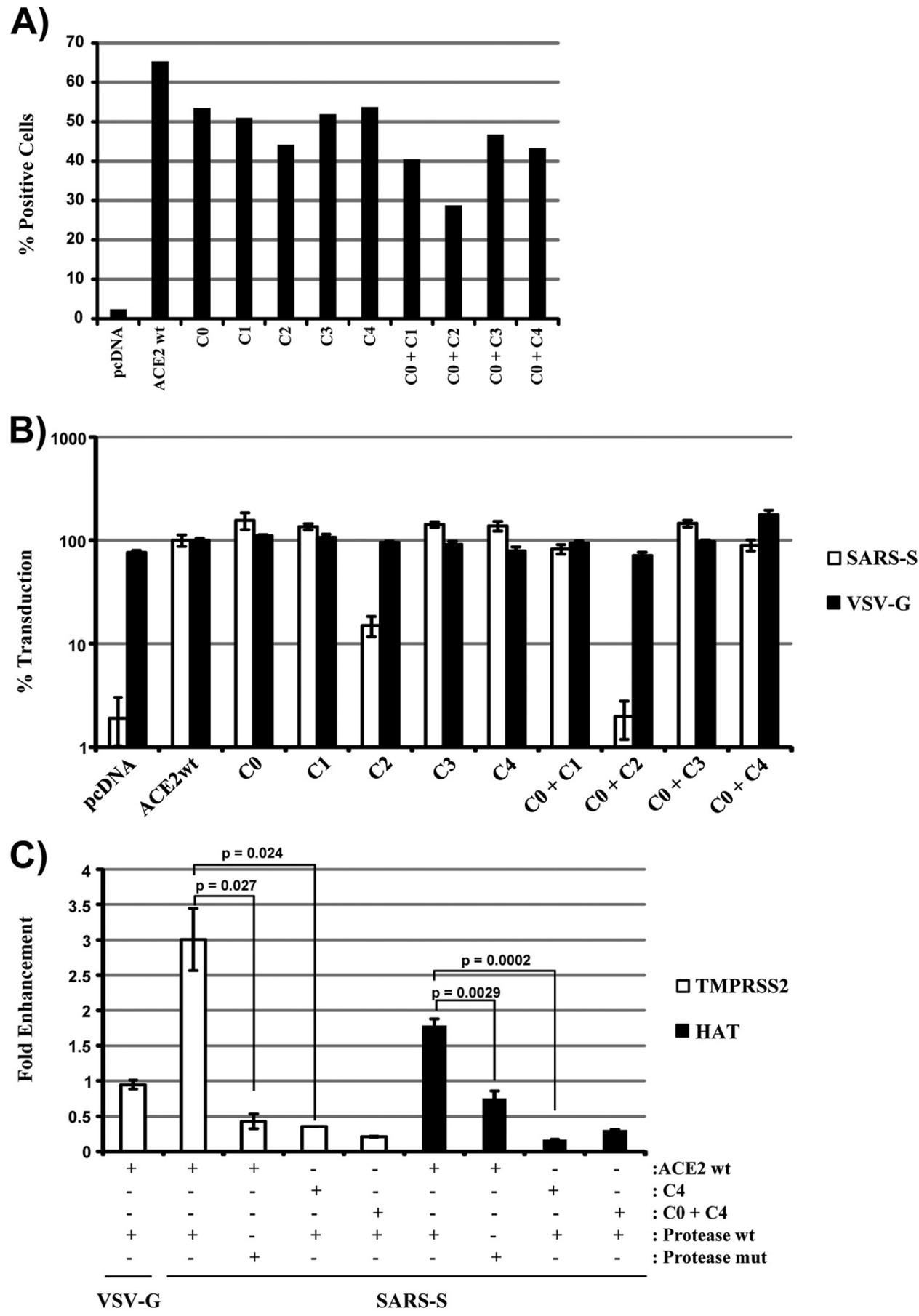

FIG 4 Arginine and lysine residues with ACE2 amino acids 697 to 716 are essential for TMPRSS2- and HAT-dependent augmentation of entry mediated by the SARS-CoV spike protein. (A) Plasmids encoding the ACE2 wt or the indicated ACE2 mutants were transiently transfected into 293T cells, and ACE2 surface expression was detected by FACS. Results of a single experiment are shown and were confirmed in two separate experiments. (B) Plasmids encoding the ACE2 wt or the indicated ACE2 mutants were transiently transfected into 293T cells and the cells transduced with a lentiviral vector pseudotyped with SARS-S. Cells transfected with empty plasmid ( $\mathrm{pcDNA}$ ) served as a negative control, while a vector pseudotyped with VSV-G served as a control for susceptibility to ACE2-independent transduction. Luciferase activities in cell lysates were determined at $72 \mathrm{~h}$ postransduction. The results of a representative experiment performed with triplicate samples are shown; error bars indicate standard deviations (SD). Similar results were obtained in two additional experiments. (C) The experiment was carried out as described for panel B, but transduction of target cells expressing the ACE2 wt or the indicated ACE2 mutants jointly with the indicated proteases was assessed. The results are shown as fold enhancement of transduction upon expression of the proteases TMPRSS2 and HAT. The results represent the averages from two to six independent experiments, and error bars indicate SEM. 


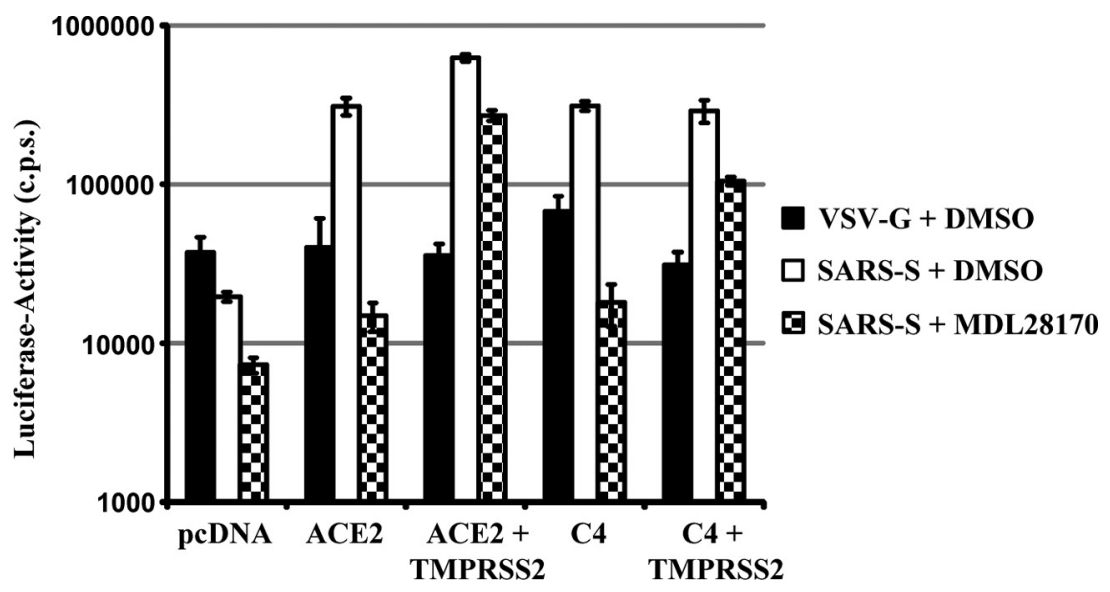

FIG 5 ACE2 cleavage is dispensable for SARS-S activation by TMPRSS2. Plasmids encoding the ACE2 wt or ACE2 mutant C4 were transiently cotransfected into 293T cells with either plasmid encoding TMPRSS2 or empty plasmid. Subsequently, the cells were incubated with the cathepsin B/L inhibitor MDL28170 or an equal volume of dimethyl sulfoxide (DMSO) and transduced with pseudotypes bearing the indicated glycoproteins. Luciferase activities in cell lysates were determined at $72 \mathrm{~h}$ posttransfection. The results of a representative experiment performed with triplicate samples are shown, and error bars indicate SD. Comparable results were obtained in two separate experiments.

ACE2 mutants was robust, although mutation of one and particularly two arginine and lysine clusters invariably caused a modest decrease in ACE2 expression levels (Fig. 4A). A more notable reduction in ACE2 surface expression was measured upon mutation of cluster 2 (mutants $\mathrm{C} 2$ and $\mathrm{C} 0+\mathrm{C} 2$ ) (Fig. 4A), in keeping with the reduced expression of these mutants in cell lysates (Fig. 3B and C).

The receptor activity of the ACE2 mutants mirrored their expression profile: most ACE2 mutants analyzed, including the protease-resistant mutants $\mathrm{C} 4$ and $\mathrm{C} 0+\mathrm{C} 4$, supported transduction by SARS-S-bearing pseudotypes with an efficiency similar to that of the ACE2 wt (Fig. 4B). In contrast, a 5- and 50-fold-reduced transduction efficiency was measured for mutants $\mathrm{C} 2$ and $\mathrm{C} 0+$ C2, respectively (Fig. 4B).

In order to investigate protease-dependent enhancement of infectivity, the ACE2 wt or ACE2 mutants $\mathrm{C} 4$ and $\mathrm{C} 0+\mathrm{C} 4$ were coexpressed with TMPRSS2 or HAT, and the efficiency of SARSS-mediated transduction was examined. Coexpression of the ACE2 wt with TMPRSS2 and to a lesser degree with HAT augmented SARS-S- but not VSV-G-driven entry (Fig. 4C), as expected (28). In addition, augmentation of entry was dependent on the enzymatic activity of the proteases (Fig. 4C), again in keeping with published results (28). In contrast, expression of TMPRSS2 and HAT did not increase SARS-S-mediated entry into cells expressing the cleavage-resistant ACE2 mutants $\mathrm{C} 4$ and $\mathrm{C} 0+\mathrm{C} 4$ (Fig. 4C), demonstrating that ACE2 proteolysis is essential for the protease-dependent augmentation of SARS-S-driven cellular entry.

ACE2 proteolysis by TMPRSS2 is not required for SARS-Sactivation. The expression of TMPRSS2 in viral target cells can increase entry efficiency (Fig. 4C) (28) and allows for cathepsin L-independent SARS-S activation (26-28). The first phenotype, increased infection, is due to ACE2 cleavage, as demonstrated above. The second phenotype, cathepsin L independence, has so far been linked to SARS-S cleavage but could also depend on ACE2 proteolysis. To address this question, we asked whether TMPRSS2 expression also facilitates cathepsin L-independent entry into target cells expressing the cleavage-resistant ACE2 mutant C4. For this, the ACE2 wt or ACE2 mutant C4 were expressed in 293T cells, and the cells were treated with PBS or cathepsin B/L inhibitor MDL28170 and transduced by pseudotypes bearing VSV-G or SARS-S. All cells were readily transduced by pseudotypes bearing VSV-G (Fig. 5). Transduction facilitated by SARS-S was profoundly augmented upon expression of the ACE2 wt, and a further increase was observed upon coexpression of TMPRSS2, in accord with our previous observations (Fig. 4C). Transduction of cells expressing ACE2 alone was markedly reduced upon pretreatment with MDL28170 and transduction efficiency was rescued upon coexpression of TMPRSS2, in agreement with published data (26-28). Notably, the same effects were observed for cells expressing ACE2 mutant C4 in conjunction with TMPRSS2 (Fig. 5), demonstrating that ACE2 cleavage is not required for TMPRSS2-mediated, cathepsin L-independent entry into target cells.

TMPRSS2 increases cellular uptake of SARS-S. The results obtained so far demonstrated that ACE2 cleavage is essential for augmentation of SARS-S-dependent entry by TMPRSS2 and HAT expression. In order to obtain insights into the underlying mechanism, we first investigated whether expression of TMPRSS2 facilitates SARS-S binding to cells. The soluble S1 subunit of SARS-S fused to human Fc (SARS-S1-Fc) bound efficiently to ACE2-expressing cells, while binding to TMPRSS2-positive cells was within the background range (Fig. 6A), and comparable results were obtained upon analysis of SARS-S1-Fc binding by immunofluorescence (data not shown). These results suggest that increased SARS-S binding does not account for the ability of TMPRSS2 to augment SARS-S-driven entry. Next, we assessed whether protease expression facilitates SARS-S uptake into target cells. For this, we incubated cells expressing ACE2 or coexpressing ACE2 and TMPRSS2 with SARS-S1-Fc and examined the cellular localization of ACE2 and SARS-S1-Fc by confocal microscopy. When $293 \mathrm{~T}$ cells were incubated with SARS-S1-Fc at $4^{\circ} \mathrm{C}$, bound SARSS1-Fc and ACE2 colocalized at or close to the cell surface, and no difference was observed upon coexpression of TMPRSS2 (Fig. 6B). Similarly, both SARS-S1-Fc and ACE2 colocalized the cell surface when cells were incubated at $37^{\circ} \mathrm{C}$ (Fig. 6B). Interestingly, 


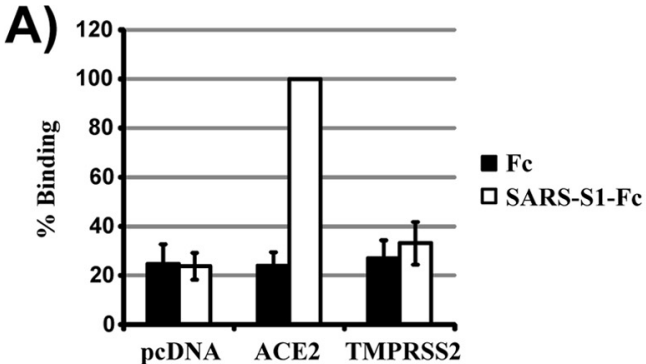

B)

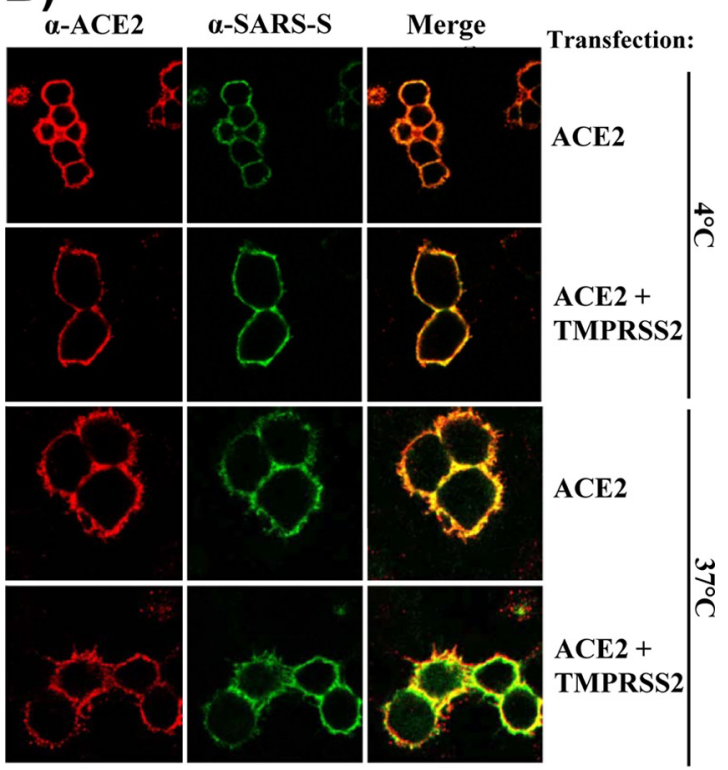

FIG 6 TMPRSS2 increases uptake of SARS-S into ACE2-expressing cells. (A) Plasmids encoding the ACE2 wt or TMPRSS2 or empty plasmid (pcDNA) were transiently transfected into $293 \mathrm{~T}$ cells and the cells incubated with the Fc-tagged S1 subunit of SARS-S (SARS-S1-Fc) for $1 \mathrm{~h}$ at $4^{\circ} \mathrm{C}$. As a negative control, cells were incubated with the Fc portion alone $(\mathrm{Fc})$. Subsequently, the cells were washed, and the amount of bound proteins was detected by FACS analysis. The geometric mean channel fluorescence was measured, and the signal obtained for SARS-S1-Fc binding to ACE2-transfected cells was set as $100 \%$. The averages from three independent experiments are shown, and error bars indicate SEM. (B) Plasmids encoding ACE2 and either TMPRSS2 or no protease were transiently cotransfected into $293 \mathrm{~T}$ cells. The transfected cells were incubated with SARS-S1-Fc for $1 \mathrm{~h}$ at $4^{\circ} \mathrm{C}$ or $37^{\circ} \mathrm{C}$. Subsequently, the cells were washed, and ACE2 and SARS-S1-Fc were detected by immunofluorescence staining and confocal microscopy. The results are representative of those of three separate experiments. $\alpha$, anti.

a slightly different result was obtained with cells coexpressing ACE2 and TMPRSS2. Again, colocalization of SARS-S1-Fc and ACE2 at the cell surface was detectable, but a substantial part of the SARS-S1 signal was now localized inside the cell, just beneath the plasma membrane, consistent with more efficient cellular uptake of SARS-S under these conditions. In contrast, an increase in SARS-S1-Fc uptake was not observed upon coexpression of TMPRSS2 and the cleavage-resistant ACE2 mutant C4 (data not shown). Thus, TMPRSS2 expression increases uptake of SARSS1-Fc and potentially authentic SARS-CoV, which might account for increased SARS-S-driven entry into TMPRSS2-positive cells.

TMPRSS2 expression inhibits SARS-S shedding by ADAM17. It has been proposed that SARS-S binding to ACE2 induces ACE2 shedding by ADAM17, which in turn increases cellular uptake of SARS-CoV $(34,35)$. In the light of these findings, we thought to clarify whether TMPRSS2 and ADAM17 modulate SARS-CoV entry via similar mechanisms. For this, we first asked whether TMPRSS2, like ADAM17, facilitates ACE2 shedding. PMA is known to induce ACE2 shedding in an ADAM17-dependent fashion (49) and was used as positive control. Indeed, PMA treatment of ACE2-expressing cells induced ACE2 release into the supernatant in a concentration-dependent fashion (Fig. 7A). In contrast, efficient ACE2 release from cells coexpressing ACE2 and TMPRSS2 was only observed upon treatment with the highest concentration of PMA examined (Fig. 7A). Similarly, constitutive shedding of ACE2, which is known to be partially ADAM17 dependent $(49,50)$, was suppressed by TMPRSS2 expression (Fig. 7A, lanes without PMA). Finally, the failure of TMPRSS2-expressing cells to release ACE2 into the supernatant was not due to retention of cleaved ACE2 at the cell surface, as determined by high-salt washes, and suppression of ACE2 shedding was dependent on the enzymatic activity of TMPRSS2 (Fig. 7B). These observations indicate that TMPRSS2 does not facilitate ACE2 shedding and even interferes with ACE2 shedding by ADAM17.

Arginine and lysine residues within amino acids 652 to 659 are essential for ACE2 shedding by ADAM17. The failure of TMPRSS2 to shed ACE2 suggests that TMPRSS2 and ADAM17 cleave ACE2 at different sites. To explore this possibility, we investigated the ADAM17 cleavage site employing our set of ACE2 mutants. The analysis of cell lysates for expression (Fig. 8, top panel) and TMPRSS2-mediated cleavage (Fig. 8, middle panel) of the ACE2 wt and mutants yielded results comparable to the ones we had obtained previously (Fig. 3), with a short C-terminal cleavage product being readily detectable for all ACE2 variants tested except mutant C4. In contrast, no C-terminal cleavage product was observed for cellular lysates upon PMA treatment of cells expressing the ACE2 wt and $\mathrm{C} 0$ to $\mathrm{C} 3$ (Fig. 8, middle panel), in keeping with the published observation that the cleavage product is instable and not readily detectable by immunoblotting $(34,51)$. A weak signal was consistently observed for mutant C4, suggesting that the amino acid changes introduced into this mutant stabilized the cleavage product. Finally, a prominent ACE2 signal was detected for supernatants of PMA-treated cells expressing the ACE2 wt and all mutants except C2 (Fig. 8, bottom panel), indicating that PMA treatment had induced ACE2 shedding and that shedding was inhibited by the changes introduced into mutant $\mathrm{C} 2$. Thus, arginine and lysine residues within amino acids 652 to 659 are critical for ADAM17-dependent ACE2 shedding.

Modulation of ADAM17 activity does not impact SARS-Sdriven entry. Having demonstrated that different determinants in ACE2 control cleavage by TMPRSS2/HAT and ADAM17, we sought to further investigate the role of ACE2 processing by ADAM17 in SARS-S-driven entry. Our previous work indicated that ADAM17 activity is not required for SARS-S-mediated transduction or for spread of authentic SARS-CoV (36), findings that contrast with those of previous studies $(34,35)$. However, the activation of ADAM17 by PMA and potentially also by SARS-S is a fast, transient process (52), which might have been missed in our previous study, since cells were incubated for prolonged times with an excess of free virus in the presence and absence of ADAM17 inhibitor (36). To address this possibility, we investigated the role of ADAM17 in SARS-S-driven entry under conditions of synchronized infection in the absence of cell-free virus. 
A)

ACE2 + pcDNA ACE2 + TMPRSS2

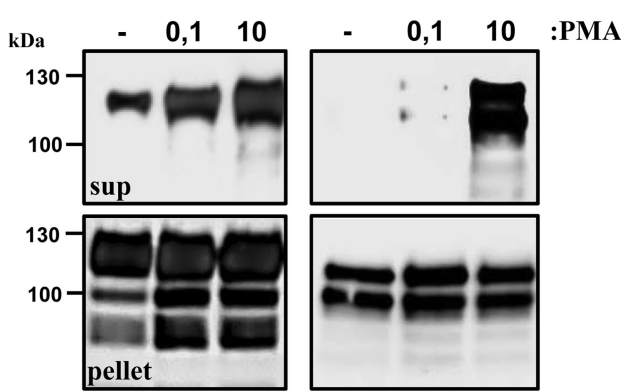

B)

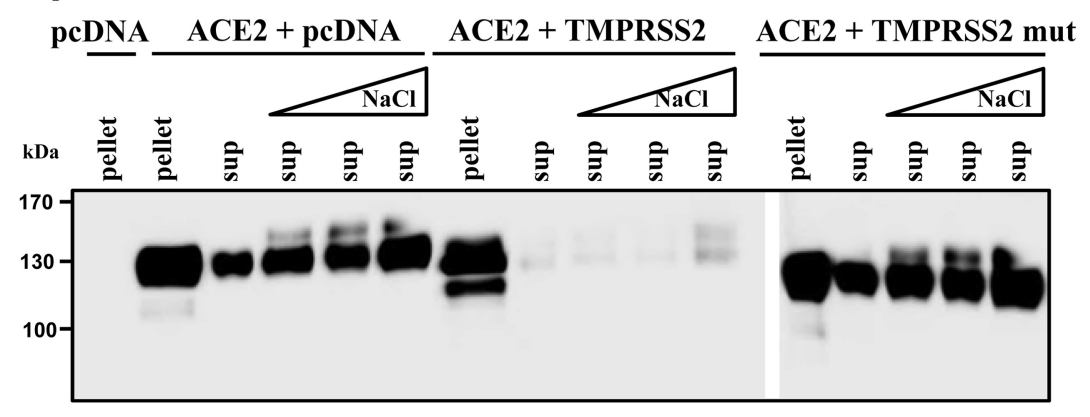

FIG 7 TMPRSS2 suppresses ACE2 shedding by ADAM17. (A) 293T cells were transiently cotransfected with plasmid encoding ACE2 and either empty plasmid (left panels) or plasmid encoding TMPRSS2 (right panels). Subsequently, cells were incubated with medium or medium supplemented with the indicated amounts of PMA, and the presence of ACE2 in culture supernatants (sup; top panel) or cell pellets (pellet; bottom panel) was examined by Western blotting employing an antibody directed against the ACE2 ectodomain. (B) 293T cells were transiently cotransfected with plasmids encoding ACE2 and either the TMPRSS2 wt or catalytically inactive TMPRSS2 (mut) or empty plasmid (pcDNA). Subsequently, supernatants were harvested and proteins precipitated (sup). The cells were pelleted, washed with buffer containing different concentrations of $\mathrm{NaCl}$, and pelleted again, and proteins present in supernatants were precipitated (sup $+\mathrm{NaCl}$ ). The presence of ACE2 in cell lysates or supernatants was analyzed by Western blotting as described for panel A.

For this, we incubated ACE2 wt-expressing 293T cells with SARSS-bearing pseudotypes at $4^{\circ} \mathrm{C}$, conditions which allow particle binding but prevent uptake. Subsequently, unbound particles were removed by washing and the cells were incubated with PMA or TAPI-1, which activates and represses ADAM17 activity, respectively. Thereafter, the compounds were removed and the transduction efficiency was quantified. Neither PMA nor TAPI-1 treatment appreciably modulated SARS-S-driven transduction under these conditions (Fig. 8B), indicating that ADAM17 activity is not required for S-protein-mediated transduction, at least in the experimental setup chosen here.

\section{DISCUSSION}

TMPRSS2 and HAT, members of the TTSP family, cleave and activate SARS-S for host cell entry $(26-28,43,53)$. A recent study indicated that TMPRSS2 and HAT also process the SARS-CoV receptor ACE2 and that expression of these proteases increases viral entry into host cells (28). However, the molecular mechanisms underlying protease-augmented cellular entry and the potential contribution of ACE2 cleavage to SARS-S activation were unknown. Here, we show that arginine and lysine residues within ACE2 amino acids 697 to 716 are essential for ACE2 cleavage by TMPRSS2 and HAT and that ACE2 processing is required for augmentation of SARS-S-driven entry but not for SARS-S activation. Moreover, we demonstrate that ADAM17, an ACE2 sheddase, requires arginine and lysine residues within ACE2 amino acids 652 to 659 for receptor cleavage and competes with TMPRSS2 for ACE2 processing. However, ADAM17 activity did not modulate SARS-S-driven entry. In sum, these results and previously published work (26-28) indicate that TMPRSS2 facilitates SARS-CoV infection via two independent mechanisms, cleavage of ACE2, which might promote viral uptake, and cleavage of SARS-S, which activates the $S$ protein for membrane fusion.

Several coronaviruses use peptidases as receptors for host cell entry: the novel coronavirus MERS binds to CD26 (54), most alphacoronaviruses use CD13, and SARS-CoV and the human coronavirus NL63 engage the carboxypeptidase ACE2 $(17,41)$.
ACE2 is an integral component of the renin-angiotensin system (RAS), which controls blood pressure as well as fluid and salt balance (55). In addition, ACE2 expression protects against acute respiratory distress syndrome $(37,38)$. ACE2 exerts its regulatory activities by facilitating the generation of the heptapeptide Ang 1-7 (55), which modulates RAS activity by signaling via the G-protein-coupled receptor MAS (56). Thus, ACE2 is intimately involved in several physiological and pathophysiological processes, and cellular factors modulating ACE2 expression, receptor function, and enzymatic activity might afford novel strategies for therapeutic intervention.

TMPRSS2 and HAT processed ACE2 in an identical fashion, with a short C-terminal ACE2 fragment of approximately $13 \mathrm{kDa}$ being consistently detectable in lysates of cells coexpressing ACE2 and protease but not ACE2 alone. Additional fragments of slightly higher molecular weights were observed upon expression of small amounts of protease and likely constitute cleavage intermediates. Shulla and colleagues previously reported identical processing of ACE2 by TMPRSS2 and HAT but noted the production of a 20 $\mathrm{kDa}$ fragment (28). The reasons for this discrepancy are at present unclear but might relate to batch-specific differences in the 293T cells employed, the use of antigenically tagged ACE2 in the published but not the present study, and most importantly, the amount of ACE2 and protease expressed. The production of the $13-\mathrm{kDa}$ ACE2 cleavage fragment was also observed upon expression of animal orthologs of TMPRSS2 and HAT, indicating that ACE2 cleavage might be conserved between humans and animals. Finally, human hepsin, a TTSP expressed in kidney, pancreas, lung, and other tissues $(57,58)$, was found to process ACE2 and SARS-S (not shown). These observations demonstrate that all SARS-S-processing TTSPs identified so far also cleave ACE2 and raise the question how ACE2 cleavage impacts SARS-S-driven entry.

Shulla and colleagues suggested that ACE2 cleavage is required for TMPRSS2 and HAT-mediated augmentation of SARS-Sdriven entry (28), but formal proof was lacking. In addition, it was not investigated whether ACE2 cleavage is required for 

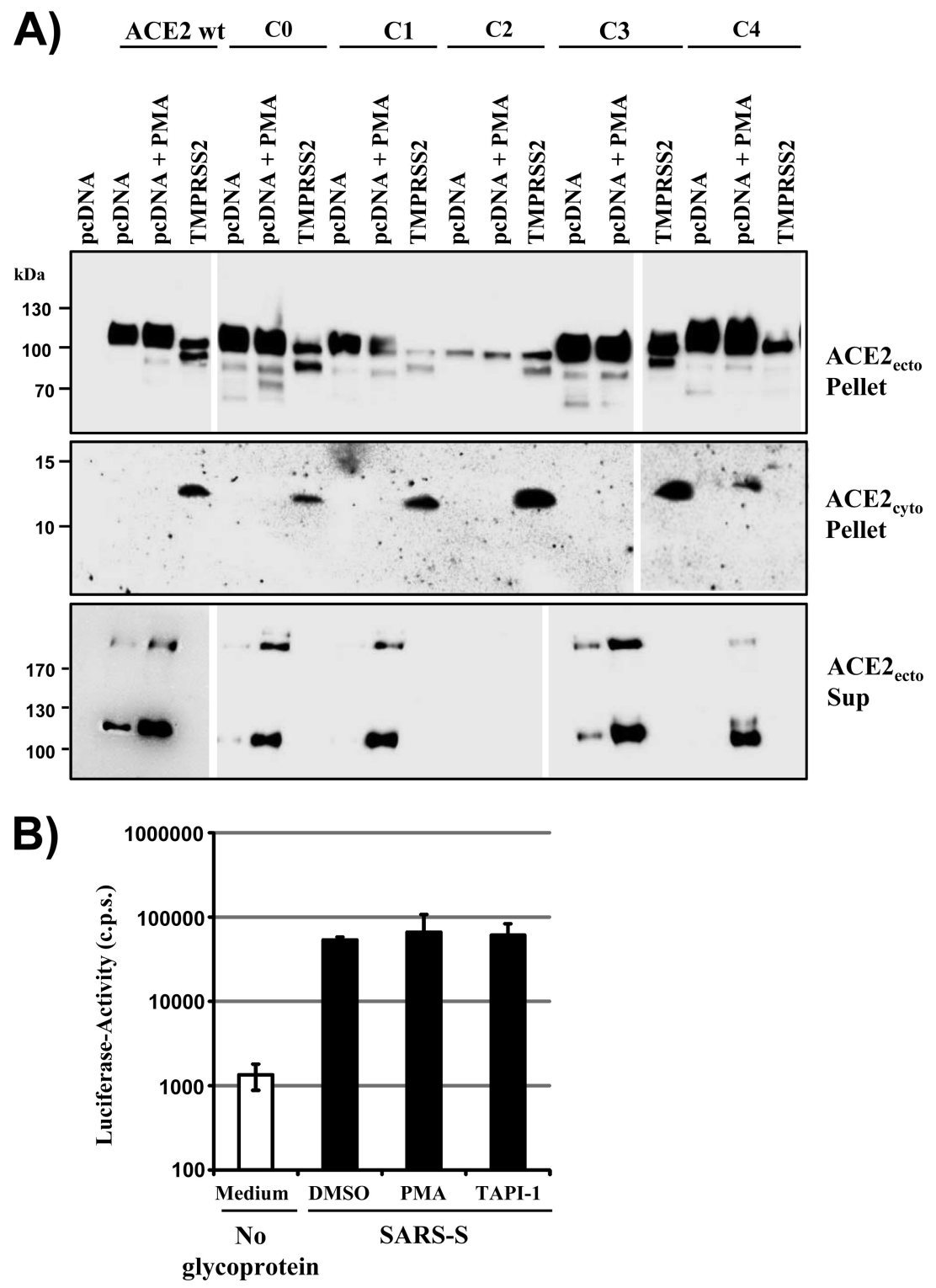

FIG 8 Arginine and lysine residues within ACE2 amino acids 652 to 659 are essential for ACE2 shedding by ADAM17. (A) 293T cells were transiently cotransfected with plasmids encoding the ACE2 wt or the indicated ACE2 mutants jointly with plasmid encoding TMPRSS2 or empty plasmid (pcDNA). The cells cotransfected with empty plasmid were cultivated in either regular medium or medium supplemented with PMA. Subsequently, ACE2 levels in cell lysates were detected by Western blotting using an ACE2 monoclonal antibody directed against the ACE2 ectodomain (top panel) or a polyclonal antibody directed against the $\mathrm{C}$ terminus of ACE2 (middle panel). In parallel, the presence of ACE2 in culture supernatants (Sup) was determined using an antibody against the ACE2 ectodomain (bottom panel). (B) A plasmid encoding the ACE2 wt was transiently transfected into $293 \mathrm{~T}$ cells, and the cells were incubated with a lentiviral vector pseudotyped with SARS-S for $1 \mathrm{~h}$ at $4^{\circ} \mathrm{C}$. A lentiviral vector bearing no glycoprotein (pcDNA) was included as a negative control. Thereafter, the cells were washed and incubated with medium containing $10 \mu \mathrm{M}$ PMA or $50 \mu \mathrm{M}$ TAPI-1 or an equal volume of DMSO at $37^{\circ} \mathrm{C}$ for $8 \mathrm{~h}$. Cells exposed to bald vector (pcDNA) were incubated in medium alone. Subsequently, the media were replaced and the cells maintained in culture medium without inhibitor. Luciferase activities in cell lysates were determined at $72 \mathrm{~h}$ postransduction. The results of a representative experiment carried out with triplicate samples are shown; error bars indicate SD. Comparable results were obtained in two separate experiments.

TMPRSS2-dependent activation of SARS-S for cathepsin L-independent entry. Answering these questions requires the identification of the protease cleavage site in ACE2. ACE2 cleavage by HAT was readily detectable upon analysis of recombinant proteins and mass spectrometric analysis identified R621 as the cleavage site. However, mutation of this residue in the context of cellular ACE2 did not interfere with processing by TMPRSS2 and HAT. Differences in the folding and/or accessibility to cleavage between the recombinant and cellular proteins might account for these differential results. Instead, arginine and lysine residues within ACE2 amino acids 697 to 716 were critical for ACE2 cleavage by TMPRSS2 and HAT, as demonstrated by mutagenic analysis of potential cleavage sites in the membrane-proximal region of ACE2. Residual ACE2 cleavage, occurring after mutation of arginine and lysine residues within 697 to 716 (ACE2 mutant C4), was largely abrogated when R621 was also mutated, suggesting a mi- 


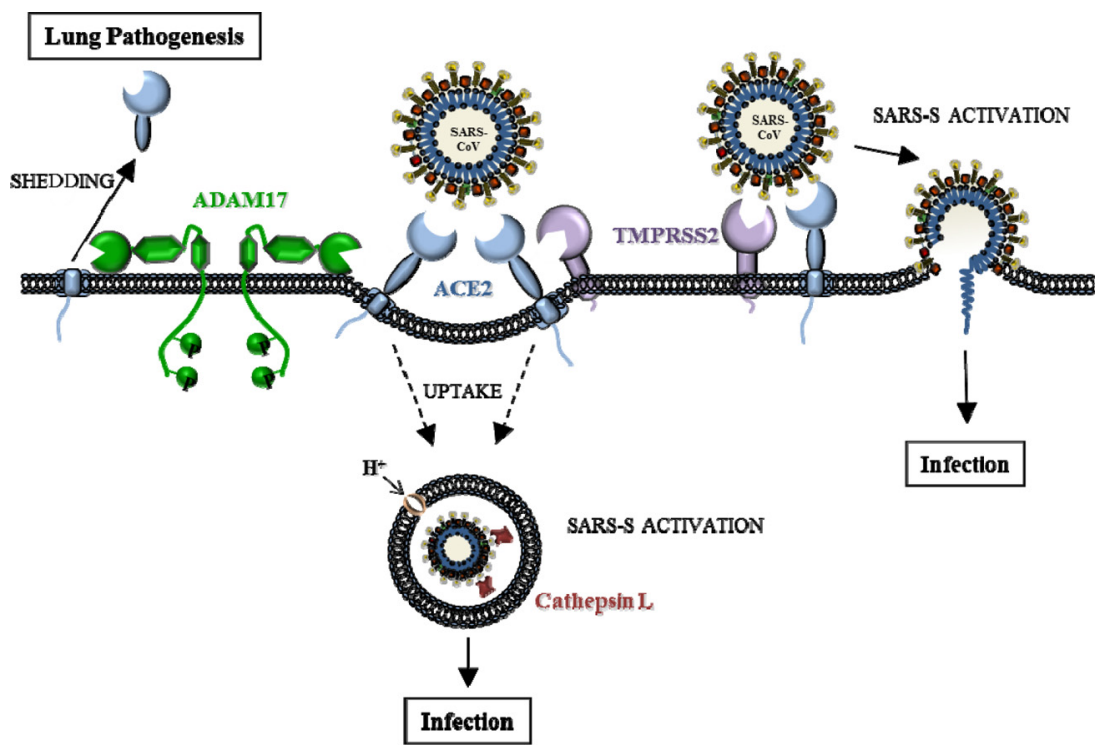

FIG 9 Role of host cell proteases in the cellular entry of SARS-CoV. Host cell entry of SARS-CoV can proceed via two distinct routes, dependent on the availability of cellular proteases required for activation of SARS-S. The first route is taken if no SARS-S-activating proteases are expressed at the cell surface. Upon binding of virion-associated SARS-S to ACE2, virions are taken up into endosomes, where SARS-S is cleaved and activated by the pH-dependent cysteine protease cathepsin L. The second route of activation can be pursued if the SARS-S-activating protease TMPRSS2 is coexpressed with ACE2 on the surface of target cells. Binding to ACE2 and processing by TMPRSS2 are believed to allow fusion at the cell surface or upon uptake into cellular vesicles but before transport of virions into host cell endosomes. Uptake can be enhanced upon SARS-S activation of ADAM17, which cleaves ACE2, resulting in shedding of ACE2 in culture supernatants. Since normal expression of ACE2 protects from lung injury and ACE2 levels are known to be reduced in SARS-CoV infection, the ADAM17dependent ACE2 shedding is believed to promote lung pathogenesis. The present study suggests that the cellular uptake of SARS-CoV can also be augmented upon ACE2 cleavage by TMPRSS2. Since the entry-promoting function of ADAM17 is not undisputed and increased uptake upon ACE2 cleavage by TMPRSS2 has only been demonstrated with soluble SARS-S1, the respective arrows are shown in dashed lines.

nor role of this residue in ACE2 processing. Collectively, these results demonstrate that arginine and lysine residues within ACE2 amino acids 697 to 716 are essential for ACE2 cleavage and, based on the molecular weight of the C-terminal cleavage product, might represent the actual cleavage site.

The cleavage-resistant ACE2 mutant C4 was robustly expressed and facilitated SARS-S-driven entry into target cells with efficiency similar to that of the ACE2 wt. Therefore, mutant C4 was used as a tool to investigate the role of ACE2 cleavage in SARS-S-driven entry. The analysis of TMPRSS2/HAT-dependent augmentation of SARS-S-mediated entry clearly revealed that ACE2 processing is a prerequisite to this process. Thus, expression of these proteases augmented entry into target cells expressing the ACE2 wt but not ACE2 mutant C4. In contrast, TMPRSS2 facilitated efficient cathepsin L-independent entry into cells expressing the ACE2 wt and mutant $\mathrm{C} 4$, demonstrating that ACE2 cleavage is dispensable for SARS-S activation. This observation is noteworthy, since ACE2 binding is believed to trigger conformational changes in SARS-S which alter the susceptibility of SARS-S to proteolytic activation by trypsin $(25,59)$. Thus, one could have assumed that cleavage by TMPRSS2 slightly alters ACE2 conformation and that only SARS-S bound to cleaved ACE2 is appropriately presented for processing by TMPRSS2, a possibility disproved by the present study. In sum, our observations indicate that TMPRSS2 and HAT impact SARS-S-driven entry via two independent mechanisms: ACE2 cleavage by these proteases increases entry efficiency, while SARS-S cleavage by TMPRSS2 activates the $S$ protein for cathepsin L-independent host cell entry (Fig. 9).

How does ACE2 cleavage by TMPRSS2 and HAT augment
SARS-S-driven entry? We did not observe substantial differences in SARS-S binding to cells expressing ACE2 or coexpressing ACE2 and TMPRSS2, demonstrating that augmentation of entry is not due to increased capture of SARS-S. Instead, we found that cells coexpressing TMPRSS2 and ACE2 internalize SARS-S more efficiently than cells expressing ACE2 alone, indicating that TMPRSS2 might promote particle uptake into receptor-positive cells. Particles taken up via cleaved ACE2 might then enter the cathepsin L-dependent pathway and fuse with the endosomal membrane (Fig. 9). Alternatively, they might be activated by TMPRSS2 and fuse with a vesicle membrane immediately after particle uptake. The molecular mechanism responsible for increased uptake is unclear at present, but we speculate that the ACE2 cleavage fragment harbors signals for internalization which might be parasitized by SARS-CoV to promote particle uptake into target cells.

The involvement of proteases in SARS-S entry is not limited to TTSPs and cathepsin L. ACE2 is cleaved by the metalloprotease ADAM17, which results in shedding of the ACE2 ectodomain (49-51). Haga and colleagues provided evidence that SARS-S also stimulates ADAM17-dependent ACE2 cleavage and that cleavage promotes uptake of authentic, infectious SARS-CoV into target cells $(34,35)$ (Fig. 9). In contrast, our previous analysis failed to detect evidence for an important contribution of ADAM17 to SARS-S-mediated cellular entry (36). In the present study, we revisited the role of ADAM17 in SARS-S-mediated entry.

We first asked whether TMPRSS2/HAT and ADAM17 cleave ACE2 at overlapping sites, which would suggest that the two proteases might regulate SARS-S-driven entry in a similar fashion. However, the comparison of ACE2 cleavage products revealed 
striking differences. The ACE2 ectodomain was shed into culture supernatants upon cleavage by ADAM17 but not TMPRSS2, although we cannot formally exclude the possibility that TMPRSS2expressing cells released into the culture supernatants an ACE2 cleavage product which was unstable and/or not detectable with the particular antibody used. In contrast, a C-terminal, intracellular cleavage fragment was observed only upon ACE2 processing by TMPRSS2, not ADAM17. The latter finding is in agreement with previous reports suggesting that the intracellular portion released from ACE2 upon cleavage by ADAM17 is unstable $(34,51$, 58). The reason for the differential shedding of the ACE2 ectodomain by ADAM17 and TMPRSS2 is at present unknown. However, the differential fate of the ACE2 cleavage products clearly indicated that these proteases cleave ACE2 at different sites. Indeed, mutagenic analysis revealed that arginine and lysine residues within ACE2 amino acids 652 to 659 are essential for ACE2 shedding by ADAM17 but do not impact ACE2 processing by TMPRSS2/HAT. Previous studies suggested that ADAM17 cleaves ACE2 at residues 708 to 709 (60) or 716 to 741 (51), respectively. Therefore, residues 652 to 659 identified in our study might not constitute the cleavage site itself but might determine whether a downstream cleavage site is recognized by ADAM17. Such a scenario is supported by previous studies suggesting that the structure of the juxtamembrane region might be more important for shedding than the sequence of the actual cleavage site $(49,61,62)$.

The ACE2 mutant resistant to ADAM17 cleavage might be useful to further dissect the role of ADAM17 in SARS-S entry, although the reduced expression or stability and receptor function of this mutant will likely complicate such endeavors. In order to commence such analyses, we first addressed if a role of ADAM17 in SARS-S-driven entry can be detected under optimized conditions, in which particles are bound to cells, unbound particles are removed, and ADAM17 is immediately activated or inhibited. However, modulation of ADAM17 activity did not impact SARSS-driven transduction, arguing against a contribution of this protease to SARS-S-mediated entry, at least under the conditions examined. On the other hand, the ACE2 mutant resistant to processing by ADAM17 failed to robustly facilitate SARS-S-driven entry even when similar amounts of ACE2 mutant and wt protein were expressed on the cell surface (due to titration of the plasmids used for transfection [data not shown]), and the nature of this defect requires further investigation.

Our study provides evidence that cleavage of ACE2 by TMPRSS2, HAT, and potentially other TTSPs could increase uptake of viral particles and is essential for protease-mediated augmentation of SARS-S-driven entry. In contrast, ACE2 processing by TMPRSS2 is dispensable for activation of SARS-S for cathepsin L-independent entry. Although some of these results await confirmation with authentic SARS-CoV, the identification of the ACE2 site(s) controlling cleavage by TTSPs and ADAM17 reveals important insights into ACE2 biology and might afford novel therapeutic strategies for treatment of lung disease. Finally, our results should stimulate efforts to determine whether receptor proteolysis impacts infection by hCoV-229E and MERS-CoV, which, like SARS-CoV, use peptidases as receptors $(54,63)$ and are activated by TTSPs $(64,65)$.

\section{ACKNOWLEDGMENTS}

We thank Marina Uecker for excellent technical support and M. Winkler for helpful discussions.
S.P., A.H., and S.G. were supported by a grant from the Bundesministerium für Bildung und Forschung (SARS Verbund, 01KI1005C).

\section{REFERENCES}

1. Holmes KV. 2001. Coronaviruses, p 1187-1203. In Knipe DM, Howley PM, Griffin DE, Lamb RA, Martin MA, Roizman B, Straus SE (ed). 2001. Fields virology, 4th ed. Lippincott Williams \& Wilkins, Philadelphia, PA.

2. Bradburne AF, Bynoe ML, Tyrrell DA. 1967. Effects of a "new" human respiratory virus in volunteers. Br. Med. J. 3:767-769. http://dx.doi.org/10 .1136/bmj.3.5568.767.

3. van der Hoek L, Pyrc K, Jebbink MF, Vermeulen-Oost W, Berkhout RJ, Wolthers KC, Wertheim-van Dillen PM, Kaandorp J, Spaargaren J, Berkhout B. 2004. Identification of a new human coronavirus. Nat. Med. 10:368-373. http://dx.doi.org/10.1038/nm1024.

4. Woo PC, Lau SK, Chu CM, Chan KH, Tsoi HW, Huang Y, Wong BH, Poon RW, Cai JJ, Luk WK, Poon LL, Wong SS, Guan Y, Peiris JS, Yuen KY. 2005. Characterization and complete genome sequence of a novel coronavirus, coronavirus HKU1, from patients with pneumonia. J. Virol. 79:884-895. http://dx.doi.org/10.1128/JVI.79.2.884-895.2005.

5. Chiu SS, Chan KH, Chu KW, Kwan SW, Guan Y, Poon LL, Peiris JS. 2005. Human coronavirus NL63 infection and other coronavirus infections in children hospitalized with acute respiratory disease in Hong Kong, China. Clin. Infect. Dis. 40:1721-1729. http://dx.doi.org/10.1086 /430301.

6. Gorse GJ, O’Connor TZ, Hall SL, Vitale JN, Nichol KL. 2009. Human coronavirus and acute respiratory illness in older adults with chronic obstructive pulmonary disease. J. Infect. Dis. 199:847-857. http://dx.doi.org /10.1086/597122.

7. Jean A, Quach C, Yung A, Semret M. 2013. Severity and outcome associated with human coronavirus OC43 infections among children. Pediatr. Infect. Dis. J. 32:325-329. http://dx.doi.org/10.1097/INF .0b013e3182812787.

8. Jevšnik M, Uršič T, Zigon N, Lusa L, Krivec U, Petrovec M. 2012. Coronavirus infections in hospitalized pediatric patients with acute respiratory tract disease. BMC Infect. Dis. 12:365. http://dx.doi.org/10.1186 /1471-2334-12-365.

9. Guan Y, Zheng BJ, He YQ, Liu XL, Zhuang ZX, Cheung CL, Luo SW, Li PH, Zhang LJ, Guan YJ, Butt KM, Wong KL, Chan KW, Lim W, Shortridge KF, Yuen KY, Peiris JS, Poon LL. 2003. Isolation and characterization of viruses related to the SARS coronavirus from animals in southern China. Science 302:276-278. http://dx.doi.org/10.1126/science .1087139 .

10. Lau SK, Woo PC, Li KS, Huang Y, Tsoi HW, Wong BH, Wong SS, Leung SY, Chan KH, Yuen KY. 2005. Severe acute respiratory syndrome coronavirus-like virus in Chinese horseshoe bats. Proc. Natl. Acad. Sci. U. S. A. 102:14040-14045. http://dx.doi.org/10.1073/pnas.0506735102.

11. Li W, Shi Z, Yu M, Ren W, Smith C, Epstein JH, Wang H, Crameri G, Hu Z, Zhang H, Zhang J, McEachern J, Field H, Daszak P, Eaton BT, Zhang S, Wang LF. 2005. Bats are natural reservoirs of SARS-like coronaviruses. Science 310:676-679. http://dx.doi.org/10.1126/science .1118391.

12. Peiris JS, Guan Y, Yuen KY. 2004. Severe acute respiratory syndrome. Nat. Med. 10:S88-S97. http://dx.doi.org/10.1038/nm1143.

13. Zaki AM, van BS, Bestebroer TM, Osterhaus AD, Fouchier RA. 2012. Isolation of a novel coronavirus from a man with pneumonia in Saudi Arabia. N. Engl. J. Med. 367:1814-1820. http://dx.doi.org/10.1056 /NEJMoa1211721.

14. World Health Organization. 4 November 2013. Middle East respiratory syndrome coronavirus (MERS-CoV) - update. http://www.who.int/csr /don/2013_11_04/en/index.html.

15. Gallagher TM, Buchmeier MJ. 2001. Coronavirus spike proteins in viral entry and pathogenesis. Virology 279:371-374. http://dx.doi.org/10.1006 /viro.2000.0757.

16. Hofmann H, Pöhlmann S. 2004. Cellular entry of the SARS coronavirus. Trends Microbiol. 12:466-472. http://dx.doi.org/10.1016/j.tim.2004.08 .008 .

17. Li W, Moore MJ, Vasilieva N, Sui J, Wong SK, Berne MA, Somasundaran M, Sullivan JL, Luzuriaga K, Greenough TC, Choe H, Farzan M. 2003. Angiotensin-converting enzyme 2 is a functional receptor for the SARS coronavirus. Nature 426:450-454. http://dx.doi.org/10 .1038 /nature02145.

18. Wang P, Chen J, Zheng A, Nie Y, Shi X, Wang W, Wang G, Luo M, Liu 
H, Tan L, Song X, Wang Z, Yin X, Qu X, Wang X, Qing T, Ding M, Deng H. 2004. Expression cloning of functional receptor used by SARS coronavirus. Biochem. Biophys. Res. Commun. 315:439-444. http://dx .doi.org/10.1016/j.bbrc.2004.01.076.

19. Hamming I, Timens W, Bulthuis ML, Lely AT, Navis GJ, van Goor H. 2004. Tissue distribution of ACE2 protein, the functional receptor for SARS coronavirus: a first step in understanding SARS pathogenesis. J. Pathol. 203:631-637. http://dx.doi.org/10.1002/path.1570.

20. Mossel EC, Wang J, Jeffers S, Edeen KE, Wang S, Cosgrove GP, Funk CJ, Manzer R, Miura TA, Pearson LD, Holmes KV, Mason RJ. 2008. SARS-CoV replicates in primary human alveolar type II cell cultures but not in type I-like cells. Virology 372:127-135. http://dx.doi.org/10.1016/j virol.2007.09.045.

21. To KF, Lo AW. 2004. Exploring the pathogenesis of severe acute respiratory syndrome (SARS): the tissue distribution of the coronavirus (SARS$\mathrm{CoV}$ ) and its putative receptor, angiotensin-converting enzyme 2 (ACE2). J. Pathol. 203:740-743. http://dx.doi.org/10.1002/path.1597.

22. To KF, Tong JH, Chan PK, Au FW, Chim SS, Chan KC, Cheung JL, Liu EY, Tse GM, Lo AW, Lo YM, Ng HK. 2004. Tissue and cellular tropism of the coronavirus associated with severe acute respiratory syndrome: an in-situ hybridization study of fatal cases. J. Pathol. 202:157-163. http://dx .doi.org/10.1002/path.1510.

23. Wong SK, Li W, Moore MJ, Choe H, Farzan M. 2004. A 193-amino acid fragment of the SARS coronavirus S protein efficiently binds angiotensinconverting enzyme 2. J. Biol. Chem. 279:3197-3201. http://dx.doi.org/10 1074/jbc.C300520200.

24. Li F, Berardi M, Li W, Farzan M, Dormitzer PR, Harrison SC. 2006. Conformational states of the severe acute respiratory syndrome coronavirus spike protein ectodomain. J. Virol. 80:6794-6800. http://dx.doi.org /10.1128/JVI.02744-05.

25. Simmons G, Gosalia DN, Rennekamp AJ, Reeves JD, Diamond SL, Bates P. 2005. Inhibitors of cathepsin L prevent severe acute respiratory syndrome coronavirus entry. Proc. Natl. Acad. Sci. U. S. A. 102:1187611881. http://dx.doi.org/10.1073/pnas.0505577102.

26. Glowacka I, Bertram S, Muller MA, Allen P, Soilleux E, Pfefferle S, Steffen I, Tsegaye TS, He Y, Gnirss K, Niemeyer D, Schneider H, Drosten C, Pöhlmann S. 2011. Evidence that TMPRSS2 activates the severe acute respiratory syndrome coronavirus spike protein for membrane fusion and reduces viral control by the humoral immune response. J. Virol. 85:4122-4134. http://dx.doi.org/10.1128/JVI.02232-10.

27. Matsuyama S, Nagata N, Shirato K, Kawase M, Takeda M, Taguchi F. 2010. Efficient activation of the severe acute respiratory syndrome coronavirus spike protein by the transmembrane protease TMPRSS2. J. Virol. 84:12658-12664. http://dx.doi.org/10.1128/JVI.01542-10.

28. Shulla A, Heald-Sargent T, Subramanya G, Zhao J, Perlman S, Gallagher T. 2011. A transmembrane serine protease is linked to the severe acute respiratory syndrome coronavirus receptor and activates virus entry. J. Virol. 85:873-882. http://dx.doi.org/10.1128/JVI.02062-10.

29. Bertram S, Heurich A, Lavender H, Gierer S, Danisch S, Perin P, Lucas JM, Nelson PS, Pöhlmann S, Soilleux EJ. 2012. Influenza and SARScoronavirus activating proteases TMPRSS2 and HAT are expressed at multiple sites in human respiratory and gastrointestinal tracts. PLoS One 7:e35876. http://dx.doi.org/10.1371/journal.pone.0035876.

30. Kawase M, Shirato K, van der Hoek L, Taguchi F, Matsuyama S. 2012. Simultaneous treatment of human bronchial epithelial cells with serine and cysteine protease inhibitors prevents severe acute respiratory syndrome coronavirus entry. J. Virol. 86:6537-6545. http://dx.doi.org/10 $.1128 /$ JVI.00094-12.

31. Böttcher E, Matrosovich T, Beyerle M, Klenk HD, Garten W, Matrosovich M. 2006. Proteolytic activation of influenza viruses by serine proteases TMPRSS2 and HAT from human airway epithelium. J. Virol. 80: 9896-9898. http://dx.doi.org/10.1128/JVI.01118-06.

32. Chaipan C, Kobasa D, Bertram S, Glowacka I, Steffen I, Tsegaye TS, Takeda M, Bugge TH, Kim S, Park Y, Marzi A, Pöhlmann S. 2009. Proteolytic activation of the 1918 influenza virus hemagglutinin. J. Virol. 83:3200-3211. http://dx.doi.org/10.1128/JVI.02205-08.

33. Shirogane Y, Takeda M, Iwasaki M, Ishiguro N, Takeuchi H, Nakatsu Y, Tahara M, Kikuta H, Yanagi Y. 2008. Efficient multiplication of human metapneumovirus in Vero cells expressing the transmembrane serine protease TMPRSS2. J. Virol. 82:8942-8946. http://dx.doi.org/10 $.1128 /$ JVI.00676-08.

34. Haga S, Yamamoto N, Nakai-Murakami C, Osawa Y, Tokunaga K, Sata T, Yamamoto N, Sasazuki T, Ishizaka Y. 2008. Modulation of
TNF-alpha-converting enzyme by the spike protein of SARS-CoV and ACE2 induces TNF-alpha production and facilitates viral entry. Proc. Natl. Acad. Sci. U. S. A. 105:7809-7814. http://dx.doi.org/10.1073 /pnas.0711241105.

35. Haga S, Nagata N, Okamura T, Yamamoto N, Sata T, Yamamoto N, Sasazuki T, Ishizaka Y. 2010. TACE antagonists blocking ACE2 shedding caused by the spike protein of SARS-CoV are candidate antiviral compounds. Antiviral Res. 85:551-555. http://dx.doi.org/10.1016/j.antiviral .2009 .12 .001

36. Glowacka I, Bertram S, Herzog P, Pfefferle S, Steffen I, Muench MO, Simmons G, Hofmann H, Kuri T, Weber F, Eichler J, Drosten C, Pöhlmann S. 2010. Differential downregulation of ACE2 by the spike proteins of severe acute respiratory syndrome coronavirus and human coronavirus NL63. J. Virol. 84:1198-1205. http://dx.doi.org/10.1128/JVI $.01248-09$.

37. Imai Y, Kuba K, Rao S, Huan Y, Guo F, Guan B, Yang P, Sarao R, Wada T, Leong-Poi H, Crackower MA, Fukamizu A, Hui CC, Hein L, Uhlig S, Slutsky AS, Jiang C, Penninger JM. 2005. Angiotensin-converting enzyme 2 protects from severe acute lung failure. Nature 436:112-116. http://dx.doi.org/10.1038/nature03712.

38. Kuba K, Imai Y, Rao S, Gao H, Guo F, Guan B, Huan Y, Yang P, Zhang Y, Deng W, Bao L, Zhang B, Liu G, Wang Z, Chappell M, Liu Y, Zheng D, Leibbrandt A, Wada T, Slutsky AS, Liu D, Qin C, Jiang C, Penninger JM. 2005. A crucial role of angiotensin converting enzyme 2 (ACE2) in SARS coronavirus-induced lung injury. Nat. Med. 11:875-879. http://dx .doi.org/10.1038/nm1267.

39. Hofmann H, Hattermann K, Marzi A, Gramberg T, Geier M, Krumbiegel M, Kuate S, Uberla K, Niedrig M, Pöhlmann S. 2004. S protein of severe acute respiratory syndrome-associated coronavirus mediates entry into hepatoma cell lines and is targeted by neutralizing antibodies in infected patients. J. Virol. 78:6134-6142. http://dx.doi.org/10.1128/JVI.78 .12.6134-6142.2004.

40. Simmons G, Reeves JD, Grogan CC, Vandenberghe LH, Baribaud F, Whitbeck JC, Burke E, Buchmeier MJ, Soilleux EJ, Riley JL, Doms RW, Bates P, Pöhlmann S. 2003. DC-SIGN and DC-SIGNR bind ebola glycoproteins and enhance infection of macrophages and endothelial cells. Virology 305:115-123. http://dx.doi.org/10.1006/viro.2002.1730.

41. Hofmann H, Pyrc K, van der Hoek L, Geier M, Berkhout B, Pöhlmann S. 2005. Human coronavirus NL63 employs the severe acute respiratory syndrome coronavirus receptor for cellular entry. Proc. Natl. Acad. Sci. U. S. A. 102:7988-7993. http://dx.doi.org/10.1073/pnas.0409465102.

42. Bertram S, Glowacka I, Blazejewska P, Soilleux E, Allen P, Danisch S, Steffen I, Choi SY, Park Y, Schneider H, Schughart K, Pöhlmann S. 2010. TMPRSS2 and TMPRSS4 facilitate trypsin-independent spread of influenza virus in Caco-2 cells. J. Virol. 84:10016-10025. http://dx.doi.org /10.1128/JVI.00239-10.

43. Bertram S, Glowacka I, Muller MA, Lavender H, Gnirss K, Nehlmeier I, Niemeyer D, He Y, Simmons G, Drosten C, Soilleux EJ, Jahn O, Steffen I, Pöhlmann S. 2011. Cleavage and activation of the severe acute respiratory syndrome coronavirus spike protein by human airway trypsin-like protease. J. Virol. 85:13363-13372. http://dx .doi.org/10.1128/JVI.05300-11.

44. Niwa H, Yamamura K, Miyazaki J. 1991. Efficient selection for highexpression transfectants with a novel eukaryotic vector. Gene 108:193199. http://dx.doi.org/10.1016/0378-1119(91)90434-D.

45. Connor RI, Chen BK, Choe S, Landau NR. 1995. Vpr is required for efficient replication of human immunodeficiency virus type-1 in mononuclear phagocytes. Virology 206:935-944. http://dx.doi.org/10.1006 /viro.1995.1016.

46. Schneider CA, Rasband WS, Eliceiri KW. 2012. NIH Image to ImageJ: 25 years of image analysis. Nat. Methods 9:671-675. http://dx.doi.org/10 .1038/nmeth.2089.

47. Jahn O, Hesse D, Reinelt M, Kratzin HD. 2006. Technical innovations for the automated identification of gel-separated proteins by MALDITOF mass spectrometry. Anal. Bioanal. Chem. 386:92-103. http://dx.doi .org/10.1007/s00216-006-0592-1.

48. Yasuoka S, Ohnishi T, Kawano S, Tsuchihashi S, Ogawara M, Masuda K, Yamaoka K, Takahashi M, Sano T. 1997. Purification, characterization, and localization of a novel trypsin-like protease found in the human airway. Am. J. Respir. Cell Mol. Biol. 16:300-308. http://dx.doi.org/10 .1165 /ajrcmb.16.3.9070615

49. Lambert DW, Yarski M, Warner FJ, Thornhill P, Parkin ET, Smith AI, Hooper NM, Turner AJ. 2005. Tumor necrosis factor-alpha convertase 
(ADAM17) mediates regulated ectodomain shedding of the severe-acute respiratory syndrome-coronavirus (SARS-CoV) receptor, angiotensinconverting enzyme-2 (ACE2). J. Biol. Chem. 280:30113-30119. http://dx .doi.org/10.1074/jbc.M505111200.

50. Iwata M, Silva Enciso JE, Greenberg BH. 2009. Selective and specific regulation of ectodomain shedding of angiotensin-converting enzyme 2 by tumor necrosis factor alpha-converting enzyme. Am. J. Physiol. Cell Physiol. 297:C1318-C1329. http://dx.doi.org/10.1152/ajpcell .00036 .2009 .

51. Jia HP, Look DC, Tan P, Shi L, Hickey M, Gakhar L, Chappell MC, Wohlford-Lenane C, McCray PB, Jr. 2009. Ectodomain shedding of angiotensin converting enzyme 2 in human airway epithelia. Am. J. Physiol. Lung Cell. Mol. Physiol. 297:L84-L96. http://dx.doi.org/10.1152 /ajplung.00071.2009.

52. Le Gall SM, Maretzky T, Issuree PD, Niu XD, Reiss K, Saftig P, Khokha R, Lundell D, Blobel CP. 2010. ADAM17 is regulated by a rapid and reversible mechanism that controls access to its catalytic site. J. Cell Sci. 123:3913-3922. http://dx.doi.org/10.1242/jcs.069997.

53. Simmons G, Zmora P, Gierer S, Heurich A, Pöhlmann S. 2013. Proteolytic activation of the SARS-coronavirus spike protein: Cutting enzymes at the cutting edge of antiviral research. Antiviral Res. 100:605-614. http://dx.doi.org/10.1016/j.antiviral.2013.09.028.

54. Raj VS, Mou H, Smits SL, Dekkers DH, Muller MA, Dijkman R, Muth D, Demmers JA, Zaki A, Fouchier RA, Thiel V, Drosten C, Rottier PJ, Osterhaus AD, Bosch BJ, Haagmans BL. 2013. Dipeptidyl peptidase 4 is a functional receptor for the emerging human coronavirus-EMC. Nature 495:251-254. http://dx.doi.org/10.1038/nature12005.

55. Kuba K, Imai Y, Ohto-Nakanishi T, Penninger JM. 2010. Trilogy of ACE2: a peptidase in the renin-angiotensin system, a SARS receptor, and a partner for amino acid transporters. Pharmacol. Ther. 128:119-128. http: //dx.doi.org/10.1016/j.pharmthera.2010.06.003.

56. Santos RA, Simoes e Silva AC, Maric C, Silva DM, Machado RP, de B, Heringer-Walther IS, Pinheiro SV, Lopes MT, Bader M, Mendes EP, Lemos VS, Campagnole-Santos MJ, Schultheiss HP, Speth R, Walther T. 2003. Angiotensin-(1-7) is an endogenous ligand for the G proteincoupled receptor Mas. Proc. Natl. Acad. Sci. U. S. A. 100:8258-8263. http: //dx.doi.org/10.1073/pnas.1432869100.

57. Leytus SP, Loeb KR, Hagen FS, Kurachi K, Davie EW. 1988. A novel trypsin-like serine protease (hepsin) with a putative transmembrane do- main expressed by human liver and hepatoma cells. Biochemistry 27 : 1067-1074. http://dx.doi.org/10.1021/bi00403a032.

58. Tsuji A, Torres-Rosado A, Arai T, Le Beau MM, Lemons RS, Chou SH, Kurachi K. 1991. Hepsin, a cell membrane-associated protease: characterization, tissue distribution, and gene localization. J. Biol. Chem. 266: $16948-16953$

59. Matsuyama S, Ujike M, Morikawa S, Tashiro M, Taguchi F. 2005. Protease-mediated enhancement of severe acute respiratory syndrome coronavirus infection. Proc. Natl. Acad. Sci. U. S. A. 102:12543-12547. http://dx.doi.org/10.1073/pnas.0503203102.

60. Lai ZW, Hanchapola I, Steer DL, Smith AI. 2011. Angiotensinconverting enzyme 2 ectodomain shedding cleavage-site identification: determinants and constraints. Biochemistry 50:5182-5194. http://dx.doi .org/10.1021/bi200525y.

61. Ehlers MR, Schwager SL, Scholle RR, Manji GA, Brandt WF, Riordan JF. 1996. Proteolytic release of membrane-bound angiotensin-converting enzyme: role of the juxtamembrane stalk sequence. Biochemistry 35: 9549-9559. http://dx.doi.org/10.1021/bi9602425.

62. Sadhukhan R, Santhamma KR, Reddy P, Peschon JJ, Black RA, Sen I. 1999. Unaltered cleavage and secretion of angiotensin-converting enzyme in tumor necrosis factor-alpha-converting enzyme-deficient mice. J. Biol. Chem. 274:10511-10516. http://dx.doi.org/10.1074/jbc.274.15.10511.

63. Delmas B, Gelfi J, L'Haridon R, Vogel LK, Sjostrom H, Noren O, Laude H. 1992. Aminopeptidase $\mathrm{N}$ is a major receptor for the enteropathogenic coronavirus TGEV. Nature 357:417-420. http://dx.doi.org /10.1038/357417a0.

64. Bertram S, Dijkman R, Habjan M, Heurich A, Gierer S, Glowacka I, Welsch K, Winkler M, Schneider H, Hofmann-Winkler H, Thiel V, Pöhlmann S. 2013. TMPRSS2 activates the human coronavirus 229E for cathepsin-independent host cell entry and is expressed in viral target cells in the respiratory epithelium. J. Virol. 87:6150-6160. http://dx.doi.org/10 .1128/JVI.03372-12

65. Gierer S, Bertram S, Kaup F, Wrensch F, Heurich A, Kramer-Kuhl A, Welsch K, Winkler M, Meyer B, Drosten C, Dittmer U, von HT, Simmons G, Hofmann H, Pöhlmann S. 2013. The spike protein of the emerging betacoronavirus EMC uses a novel coronavirus receptor for entry, can be activated by TMPRSS2, and is targeted by neutralizing antibodies. J. Virol. 87:5502-5511. http://dx.doi.org/10.1128/JVI.00128-13. 